\title{
Selective Laser Melting of Magnesium and Magnesium Alloy Powders: A Review
}

\author{
Vyasaraj Manakari, Gururaj Parande and Manoj Gupta * \\ Department of Mechanical Engineering, National University of Singapore, 9 Engineering Drive 1, \\ Singapore 117576, Singapore; mbvyasaraj@u.nus.edu (V.M.); gururaj.parande@u.nus.edu (G.P.) \\ * Correspondence: mpegm@nus.edu.sg; Tel.: +65-6516-6358 \\ Academic Editor: Hugo F. Lopez \\ Received: 9 September 2016; Accepted: 15 December 2016; Published: 26 December 2016
}

\begin{abstract}
Magnesium-based materials are used primarily in developing lightweight structures owing to their lower density. Further, being biocompatible they offer potential for use as bioresorbable materials for degradable bone replacement implants. The design and manufacture of complex shaped components made of magnesium with good quality are in high demand in the automotive, aerospace, and biomedical areas. Selective laser melting (SLM) is becoming a powerful additive manufacturing technology, enabling the manufacture of customized, complex metallic designs. This article reviews the recent progress in the SLM of magnesium based materials. Effects of SLM process parameters and powder properties on the processing and densification of the magnesium alloys are discussed in detail. The microstructure and metallurgical defects encountered in the SLM processed parts are described. Applications of SLM for potential biomedical applications in magnesium alloys are also addressed. Finally, the paper summarizes the findings from this review together with some proposed future challenges for advancing the knowledge in the SLM processing of magnesium alloy powders.
\end{abstract}

Keywords: selective laser melting (SLM); magnesium; additive manufacturing; microstructure; mechanical properties; corrosion behavior

\section{Introduction}

Magnesium (Mg) is the sixth most abundant element in the earth's crust comprising about $2.7 \%$ of its composition [1]. Magnesium based materials are preferred when targeting weight-sensitive applications, as they are the lightest structural material available with a density of only $1.74 \mathrm{~g} / \mathrm{cc}$ which is $\sim 33 \%, \sim 61 \%$ and $\sim 77 \%$ lower than that of aluminium, titanium, and iron, respectively [2]. Increasing demand for light weighting drives the interest for magnesium to be used in various engineering applications to achieve higher fuel economy, emission reduction etc. Other than its low density, magnesium based materials also exhibit high specific mechanical properties, excellent castability and machinability, high damping characteristics, high thermal stability, high thermal and electrical conductivity, and resistance to electromagnetic radiation [3-7]. However, the application areas of magnesium have been limited by its low corrosion resistance and relatively poor mechanical properties, such as low elastic modulus, low strength, limited room temperature ductility and toughness, rapid loss of strength with temperature, and poor creep resistance [8,9].

Even though magnesium based materials are not suitable where a high modulus is required, a range of applications has been evaluated in the biomaterials area in the recent past. The combination of superior biocompatibility, biodegradability, elastic modulus closer to human bone, and favourable mechanical properties makes magnesium one of the most sought after materials for orthopaedic applications like implants and fixation devices [10]. In the recent past, many magnesium alloys have been developed targeting biomedical applications ranging from maxillofacial reconstruction, to paediatric orthopaedics, vascular stents, surgical clips, screws, plates, and bone-interfacing 
implants [11-13]. Magnesium based materials have lower Young's modulus (41-45 GPa) than commonly used metallic biomaterials such as titanium (55-110 GPa), 316L stainless steel (210 GPa), and cobalt chromium alloys (240 GPa) and show no indications of local or systemic toxicity [14-16]. In addition, they are also osteo-conductive, facilitate bone cell in-growth, and have a role in cell attachment [17]. Due to these advantages, new types of magnesium implant materials have been developed which effectively aid in the mitigation of stress-shielding effects and have potential for use as a bioresorbable material for degradable bone replacement, eliminating the need of secondary surgical procedures [10]. Although magnesium has many advantages, suitable for hard tissue implant and tissue engineering scaffold material, usage of magnesium is still limited in clinical applications due to its poor formability, rapid degradation in a high chloride physiological environment and hydrogen evolution [18]. Therefore, continuous efforts are being made by researchers to develop new types of magnesium alloys and composites to meet specific property requirements and explore new processing technologies to fabricate patient-specific implant components that can be provided with additional functions to further broaden the horizon of magnesium utilization in bio-medical applications.

Magnesium based materials are usually fabricated by conventional manufacturing methods such as deformation processing, casting, and powder metallurgy (P/M) techniques. Usually lightweight engineering parts with high performance can be obtained from deformation processing of magnesium based materials. However, due to the hexagonal closed packing (HCP) structure of magnesium, magnesium alloys exhibit poor cold workability at room temperature. Deformation processing of magnesium therefore needs to be performed at elevated forming temperatures to activate more slip systems and to allow better formability, which leads to poor surface quality and oxidation of parts and limits efficiency [19]. As a result, consumption of wrought magnesium products only represent a small fraction, merely about $1.5 \%$ of total magnesium consumption [20]. Presently, casting is the most conventional and dominant synthesis route used for the manufacture of magnesium alloys and composites. Although, casting techniques ensure great efficiency with higher precision, it is difficult to fabricate near-net shape structures of complex shapes and intricate internal architectures. Moreover, it is often the case that product quality is degraded by the thermodynamically stable phases that are formed during solidification from the melt and strong oxidising tendency of magnesium [21]. It is not possible to control the morphology and/or distribution of these phases during cooling. Therefore, several $\mathrm{P} / \mathrm{M}$ routes are being explored to target unique microstructures, novel alloy compositions, and high performance in magnesium alloys [22]. Promising results were obtained by reinforcing magnesium with nanocrystalline and amorphous alloy powders. For example, $\mathrm{Mg}-\mathrm{Zn}-\mathrm{Y}$ alloys having very high tensile yield strengths in the range of 480-610 MPa with an elongation between $5 \%$ and $16 \%$ were developed using a rapidly solidified $\mathrm{P} / \mathrm{M}$ approach [23]. Also, advanced powder based manufacturing processes such as additive manufacturing (AM), cold spray, metal injection moulding, and friction stir processing are being developed to fabricate magnesium alloys having non-equilibrium compositions and limited defects [22]. These techniques can be successfully employed to design intricate and near net shaped structures. In a recent study, Tandon et al. [24] showed that magnesium alloy powders can be potentially used to manufacture and repair lightweight components for aerospace applications by using cold spray and laser assisted deposition processes.

As magnesium is expanding into a more promising lightweight regime and medical technology applications, there is a great need for intelligent selection of manufacturing processes to provide unique functional properties, crash performance, and corrosion resistance. Customised components and implants with improved mechanical and physical properties can be manufactured by additive manufacturing (AM) techniques. AM includes a whole host of "bottom up" approaches, wherein the processes involve creating three-dimensional objects fabricated directly from computer aided design (CAD) models by gradually building them up, layer-by-layer within a powder bed. Among the AM methods, laser-based AM has an immense potential for producing fully dense metallic structures using a variety of available metal powders and has attracted more and more attention [25]. Selective laser melting (SLM) is one such process that uses high intensity laser as an energy source to 
directly fuse the high-temperature metallic powder layers successively deposited one over the other as ultrathin two-dimensional cross-sections [26]. Generally, the geometrically complex components have been fabricated by SLM with a high dimensional precision and good surface integrity without other subsequent process requirements, which the conventional techniques (e.g., casting and machining) cannot keep pace with easily [27]. SLM is an efficient approach that can significantly shorten the lead time and the costs involved in the manufacturing of high-value components and offers advantages of design freedom with a wide choice of materials, reduced material wastage, and elimination of expensive tooling. Over the years, the process of SLM has become very well established for titanium alloys [28], steel and iron alloys [29], nickel base super alloys [30,31], cobalt base alloys [32], and aluminium alloys [33] and is providing an ideal platform to fabricate complex products, novel shapes, hollow and functionally graded structures to exact dimensions for the aerospace, medical, and military industries.

Despite the continuing advancement, there are very few examples that have fully utilized the potential of SLM to produce fully dense near-net shape components of magnesium and to gain an understanding of laser processability. Accordingly, this review aims to identify the advancements to date in SLM processing of magnesium and magnesium alloy powders and outlines the trend for future research to expand the application range of magnesium based materials further.

\section{Selective Laser Melting (SLM) Technology}

SLM is a powder bed fusion process, wherein selective regions of the pre-spread powder particles are melted and fused by a high intensity laser energy source in a layer by layer manner according to computer aided design (CAD) data. The term "laser" implies that a laser is used for processing, "melting" refers to the particular situation in which powders are completely melted and the term "selective" specifies that only partial powder is processed [28]. The SLM system generally is comprised of a processing laser, an automatic powder delivery system, a building platform, a controlling computer system, and main accessorial parts (e.g., inert gas system protection, roller/scrapper for powder deposition, and an overflow container) [34]. The focus and the movement of the laser beam on the build table is controlled by using a beam deflection system consisting of galvano-mirrors and a flat field-focusing lens. The entire process including the powder feeding, deposition system, scanning, temperature, atmosphere, and build are controlled by a manufacturing software. The overall processing stages of SLM include (i) designing a 3D object model of the component to be fabricated using CAD software and then slicing the designed part into many layers with every layer defined by a layer thickness (typically 20-100 $\mu \mathrm{m}$ ); (ii) a substrate is fixed and levelled for part fabrication on the build platform; (iii) a protective atmosphere (e.g., argon or nitrogen) is fed into the build chamber to minimize possible surface oxidation and hydrogen pickup; (iv) spreading of a thin layer of metal powder by powder re-coater on a substrate plate with a thickness as the aforementioned sliced layer thickness; (v) scanning/processing the powder bed in a predefined pattern in order to produce layer wise shape based on the geometry defined by the CAD model; and (vi) lowering of the building platform by a predetermined distance and repeating the last two stages for successive layers of powder until the required components are completely built. In SLM, each layer is fabricated by first generating an outline of the key component features which is referred to as contouring and subsequently the powder within the contour is melted using an appropriate scanning strategy. Once the laser scanning process is completed, specimens from the substrate plate are separated either manually or by electrical discharge machining (EDM).

SLM is a deposition welding process wherein the laser beam melts the powder particles in welding beads and shows phenomena usually observed for welding processes [26]. The physical behaviour of the SLM process includes absorption, reflection, radiation, and heat transfer, melting and coalescence of powder particles, phase transformations, a moving interface between solid phase and liquid phase, fluid flow caused by the surface tension gradient and mass transportation within the molten pool followed by solidification, and chemical reactions [26,35]. Because of the use of 
high-intensity laser, the powder particles are heated at a faster rate as the energy is absorbed via both bulk-coupling and powder-coupling mechanisms [36]. The energy is converted into heat and eventually the powder particles melt, coalesce, and form an agitated melt pool for some milliseconds (typically 0.5 to $25 \mathrm{~ms}$ ). The molten pool formed, acquires the shape of a circular or segmental cylinder under the effect of surface tension [37]. Extremely short interaction time between the laser beam and the powder bed results in the formation of a transient temperature field with a high temperature up to $10^{5}{ }^{\circ} \mathrm{C}$ and a significant rapid quenching effect with very high cooling rates up to $10^{6-8}{ }^{\circ} \mathrm{C} / \mathrm{s}$ [38] . Rapid solidification may cause development of non-equilibrium metallurgical phenomena such as microstructural refinement, solid solution hardening and the formation of metastable phases, which can have a substantial effect in improving the resultant mechanical properties and corrosion resistance of the laser processed materials $[39,40]$.

Literature has shown that components produced by SLM are completely dense and homogeneous without microscopic pores or voids and do not require any post-processing (such as infiltration with other materials or heat treatment) usually needed to improve the SLS (Selective Laser Sintered) components, other than the removal of parts and supports from the substrate plate. Another major advantage of SLM lies in its high feasibility in processing non-ferrous pure metals like $\mathrm{Ti}, \mathrm{Al}, \mathrm{Cu}, \mathrm{Mg}$, etc., which to date cannot be well processed using SLS [39]. Some common materials that have been investigated for SLM include: ferrous alloys, titanium, cobalt-chrome, nickel, aluminium, magnesium, copper, zinc, tungsten, and gold [41]. SLM also has the potential to produce components of very complex geometries with a gradient porosity which in turn allows the choice of property distribution to achieve required functions [42]. SLM is unique in that it can be used for the additive manufacturing (AM) of functionally graded and pure-metal parts, as well as for laser cladding/repair. Additive repair of damaged turbine engine hot-section components $[43,44]$ made from nickel base super alloys is one example of such repairs. SLM is also capable of multi-material processing, i.e., utilizing different feedstock materials simultaneously to produce various alloys and functionally graded materials (FGMs) $[45,46]$.

The main goal in SLM is to produce metallic parts with 100\% density. Obtaining this objective is not easy because there is no mechanical pressure during SLM, and fluid dynamics in SLM is mainly driven by gravity and capillary forces along with thermal effects. Also, the absence of mechanical pressure during the processing may lead to reduced solubility of some elements in the melt during solidification causing discontinuous melting of the tracks and formation of pores resulting in an uneven surface $[47,48]$ as shown in Figure 1a, where distribution of porosity and unmelted area within ZK60 sample produced by SLM is revealed. The materials also experience varying degrees of thermal fluctuation during the SLM process which may induce residual stresses in the laser melted layer undergoing rapid solidification [41]. This can lead to formation of hot cracks and delamination of parts as shown in Figure 1b. High heating/cooling rates during SLM can also lead to the formation of narrow heat affected zone (HAZ) around the melt pool. Presence of HAZ can alter the composition and/or microstructure of material influencing the quality and properties of the SLM-processed sample [28]. The transient thermal behaviour during the SLM process can be controlled considerably by processing parameters, such as laser power, scan speed, hatch spacing, layer thickness, and scanning pattern. Figure 2 provides an illustration of these process parameters commonly studied in SLM. These process parameters are adjusted such that a single melt vector can fuse completely with the neighbouring melt vectors and the preceding layer. Application of inappropriate processing conditions can lead to various undesirable effects such as irregularities in the surface morphology, thermal cracks, and balling effects. Therefore, it is important to establish the relationships between the principal SLM parameters and surface morphology and to optimize the SLM processing parameters to produce metallic parts with $100 \%$ density without cracks and fusion defects. 


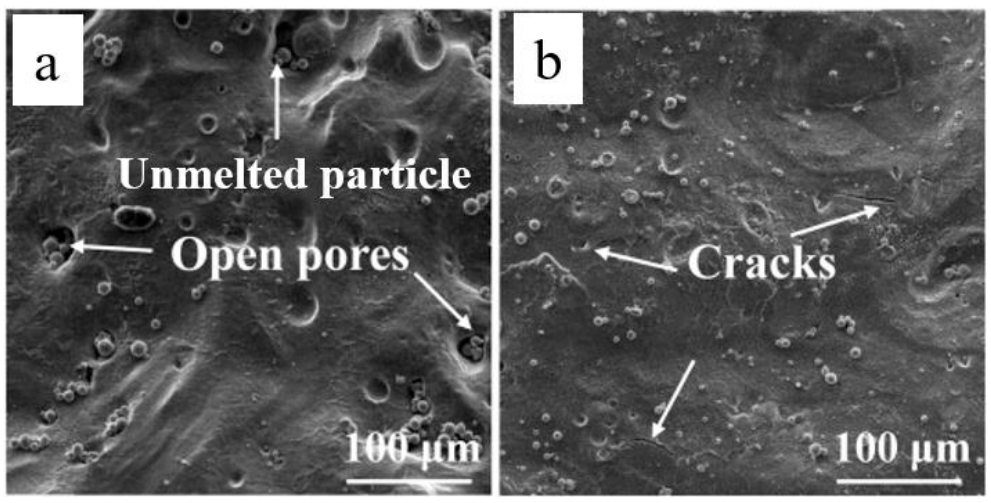

Figure 1. Scanning electron microscopy (SEM) microstructure of selective laser melting (SLM) produced ZK60 sample, showing (a) distribution of porosity and unmelted area and (b) formation of hot cracks within the ZK60 matrix [49].

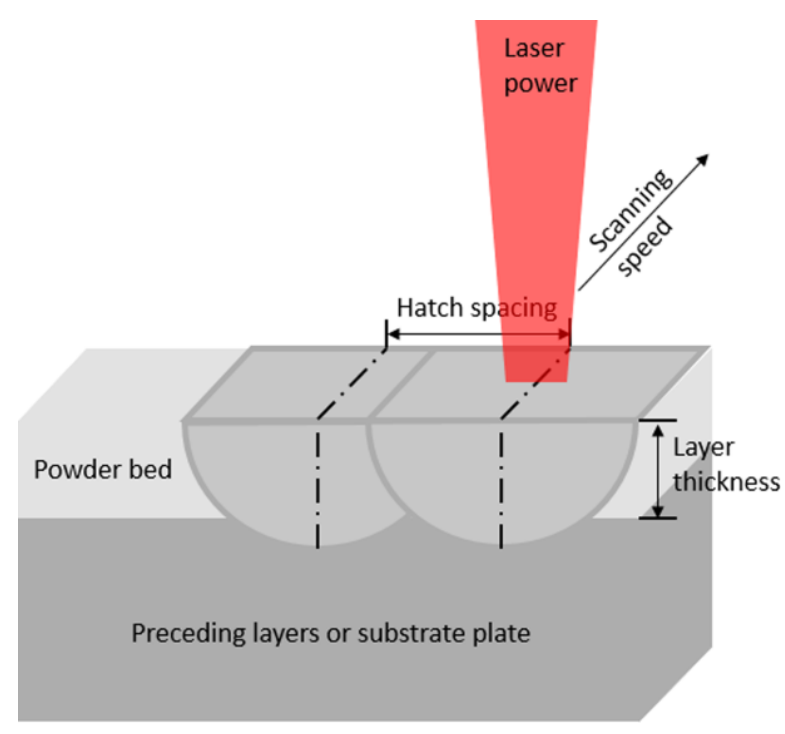

Figure 2. Schematic of SLM processing parameters [41].

\section{Effects of Processing Parameters and Powder Properties on SLM Processing and Densification of Powders}

SLM of metals requires careful selection of processing parameters to address the difficulties associated with the process such as oxidation, balling, thermal fluctuation, loss of alloying elements, and dross formation in the melt pool which lead to poor interlayer bonding, low density, instability of the tracks, crack formation, and delamination of the SLM processed part [50-52]. In order to gain a holistic understanding of the factors that influence the process of tracks formation, densification mechanism, part characteristics, and quality consistency of the fabricated parts by SLM, several processing and material parameters have been identified and are listed in Table 1 . In an attempt to overcome these inherent difficulties along with ensuring good consolidation of the deposited material layers in SLM of metals, various approaches have been employed by researchers such as combination of preheating, selection of the right scanning strategy and process parameters to ensure minimal balling, utilisation of overpressure process chamber to control the vaporisation of powders, and melting in a shielded gas atmosphere of argon or helium to moderate the oxidation process [29,53]. Accordingly, this section focuses on the possible effects of the various parameters related to laser, scan, and powder during the building process on the formability, microstructure, and resulting properties of components produced from magnesium and magnesium alloy powders. 
Table 1. Variables influencing the processing and densification mechanism of selective laser melting (SLM) processed parts [54].

\begin{tabular}{cc}
\hline SLM Processing Parameters & Material Properties \\
\hline Laser type & Viscosity \\
Laser power & Surface tension \\
Mechanical layering of powder & Thermal conductivity \\
Atmospheric control & Specific heat \\
Gas flow & Absorptivity/reflectivity \\
Heaters (bed temperature) & Emissivity \\
Scan radius & Particle size distribution \\
Scan vector length & Particle shape \\
Scan spacing & Melting Temperature \\
Scan rates & Boiling Temperature \\
Scanning time interval & Chemical composition \\
Thickness of layers & Oxidation tendency \\
\hline
\end{tabular}

\subsection{SLM Processing Windows of Magnesium and Magnesium Alloy Powders}

From their preliminary experiments, $\mathrm{Ng}$ et al. [55] were able to successfully achieve full melting of single magnesium tracks using a miniature SLM system in an inert argon gas atmosphere and demonstrated the potential to employ magnesium powders in the fabrication of objects using SLM. Further, the interactions between laser sources and magnesium powder tracks under different processing conditions, including laser powers, scanning speeds, and irradiation modes (i.e., continuous wave and pulsed mode) were investigated and the processing window for the single track formation was established [56,57]. Also, several other investigations [58-65] have focused on developing processing windows based on the formability of magnesium and magnesium alloy powders such as Mg-9\%Al, AZ91D, ZK60 and WE43 for fabricating single layer and multi-layer three dimensional parts. The details of the parameters used in these studies can be seen in Table 2. Figure 3 presents an example of a process map developed for SLM Mg-9\%Al powders in which several distinct zones are observed.

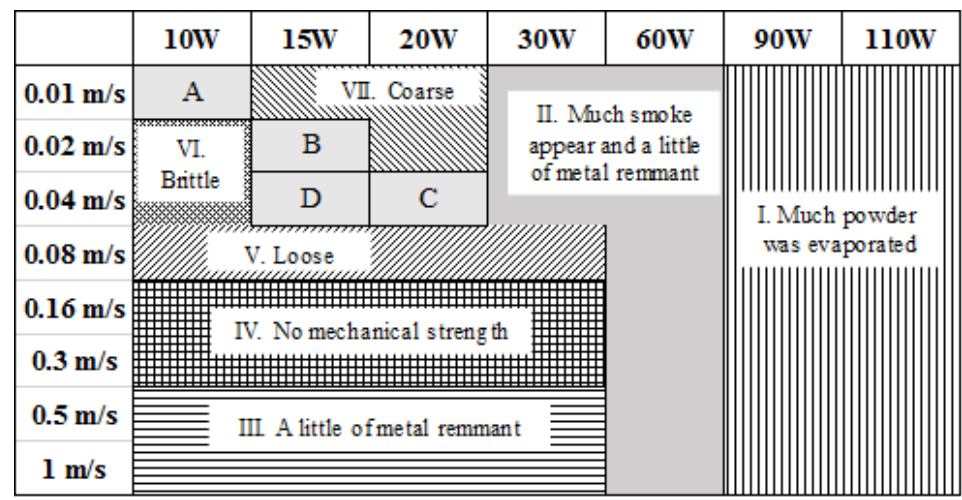

Figure 3. Process map for $\mathrm{Mg}-9 \% \mathrm{Al}$, results as function of the range of laser powers and scan speeds (modified from reference [60]).

During the process of SLM, the melting of the powder layer strongly depends on the input of laser energy supplied to the material. In this article, in order to have a single parameter to compare the processing conditions for single layer and multiple layer parts, specific laser energy density, $E$, is defined as:

$$
\begin{gathered}
E=\frac{\text { Laser power }(P)}{\text { Scanning velocity }(v) \times \text { Hatch spacing }(s)} \\
E=\frac{\text { Laser power }(P)}{\text { Scanning velocity }(v) \times \text { Hatch spacing }(s) \times \text { Layer thickness }(t)}
\end{gathered}
$$


Table 2. Manufacturing parameters that have been used in the studies.

\begin{tabular}{|c|c|c|c|c|c|c|c|c|}
\hline Materials System & Powder Characteristics & Laser Type & $\begin{array}{l}\text { Spot Size } \\
(\mu \mathrm{m})\end{array}$ & $\begin{array}{l}\text { Power } \\
\text { (W) }\end{array}$ & $\begin{array}{l}\text { Layer Thickness } \\
(\mu \mathrm{m})\end{array}$ & $\begin{array}{l}\text { Hatch Spacing } \\
(\mu \mathrm{m})\end{array}$ & $\begin{array}{c}\text { Scanning Speed } \\
(\mathrm{mm} / \mathrm{s})\end{array}$ & Scanning Pattern \\
\hline $\operatorname{Mg}[56,57]^{*}$ & $\begin{array}{l}\text { Spherical shape, mean particle size } 25 \mu \mathrm{m} \text {, } \\
\text { layer density } 0.918 \mathrm{~g} / \mathrm{cc}\end{array}$ & $\begin{array}{l}\text { Continuous and } \\
\text { pulsed wave } \\
\text { Nd:YAG Laser }\end{array}$ & 600 & $13-26$ & 500 & - & $10-200$ & $\begin{array}{l}\text { Overlap (each layer was built by } \\
\text { scanning numerous short vectors of } \\
0.65 \mathrm{~mm} \text { in the transverse direction } \\
\text { with } 98 \% \text { overlapping) }\end{array}$ \\
\hline $\operatorname{Mg}[58]^{*}$ & $\begin{array}{l}\text { Spherical shape, mean particle size } 25 \mu \mathrm{m} \text {, layer } \\
\text { density } 0.918 \mathrm{~g} / \mathrm{cc} \text {, powders were preheated for } \\
30 \mathrm{~min} \text { to reach a temperature of } 180^{\circ} \mathrm{C}\end{array}$ & $\begin{array}{l}\text { Pulsed mode } \\
\text { Nd:YAG Laser }\end{array}$ & 270 & 8.9-17.7 & $150-300$ & - & $10-200$ & - \\
\hline $\mathrm{Mg}$ [59] & $\begin{array}{c}\text { Gas atomised, spherical shape, particle size } \\
250 \text { mesh }\left(D_{50}=25.85 \mu \mathrm{m}\right) \text { with apparent } \\
\text { density of } 0.78 \mathrm{~g} / \mathrm{cc} \text { and }-400 \text { mesh } \\
\left(D_{50}=43.32 \mu \mathrm{m}\right) \text { with apparent } \\
\text { density of } 0.93 \mathrm{~g} / \mathrm{cc}\end{array}$ & $\begin{array}{l}\text { Continuous wave } \\
\text { Nd:YAG Laser }\end{array}$ & 100 & $15-150$ & 30 & 100 & $50-100$ & $\begin{array}{l}\text { Zigzag, (scanning each layer in a direction } \\
\text { rotated counter clockwise by } 63.5^{\circ} \\
\text { to its precursor) }\end{array}$ \\
\hline Mg-9\%Al [60] & $\begin{array}{l}\text { Mg-irregular shape, particle size }\left(D_{50}\right) 42 \mu \mathrm{m} \\
\text { Al-spherical shape, particle size }\left(D_{50}\right) 17 \mu \mathrm{m} \\
\text { blended for } 45 \text { min according to } \mathrm{Mg} \text { : Al weight } \\
\text { ratio of } 91: 9\end{array}$ & $\begin{array}{l}\text { Continuous wave } \\
\text { Nd:YAG laser }\end{array}$ & $34-75$ & $10-110$ & 50 & 80 & 10-1000 & Linear \\
\hline AZ91D [61] & $\begin{array}{l}\text { Gas atomised, spherical shape, mean particle } \\
\text { size } 59 \mu \mathrm{m} \text {, apparent density } 0.95 \mathrm{~g} / \mathrm{cc}\end{array}$ & $\begin{array}{l}\text { Continuous wave } \\
\text { IPG YLR-200 } \\
\text { fibre laser }\end{array}$ & 100 & 200 & 40 & $70-130$ & $166.6-1000$ & $\begin{array}{l}\text { Zigzag (scanning each layer in a direction } \\
\text { rotated by } 90^{\circ} \text { to its precursor) }\end{array}$ \\
\hline ZK60 [62] & Spherical shape, mean particle size $30 \mu \mathrm{m}$ & $\begin{array}{l}\text { Continuous wave } \\
\text { IPG YLR-200 } \\
\text { fibre laser }\end{array}$ & 150 & 200 & 20 & 80 & $100-900$ & $\begin{array}{l}\text { Zigzag (scanning each layer in a direction } \\
\text { rotated by } 90^{\circ} \text { to its precursor) }\end{array}$ \\
\hline ZK60 [49] & Spherical shape, mean particle size $50 \mu \mathrm{m}$ & Fibre laser & 150 & 50 & 100 & 100 & $6.7-11.7$ & - \\
\hline Mg-Mn [66] & $\begin{array}{l}\text { Mg-spherical shape; } \mathrm{Mn} \text {-irregular shape } \\
\text { mechanical mixing under a gas atmosphere } \\
\text { of } \mathrm{CO}_{2} \text { and } \mathrm{SF}_{6}\end{array}$ & Fibre laser & 100 & 70 & 100 & 50 & 11.7 & Linear \\
\hline $\begin{array}{l}\text { Mg-hydroxyapatite } \\
\text { (HAP) [63] }\end{array}$ & $\begin{array}{l}\text { Mg-irregular shape, particle size } 200 \mu \mathrm{m} ; \mathrm{HAP} \\
\text { particle size } 20 \mathrm{~nm} \text {; blended together according } \\
\text { to Mg:HAP volume ratio of } 98: 2\end{array}$ & $\begin{array}{l}\text { Continuous wave } \\
\text { fibre Laser }\end{array}$ & 200 & $20-120$ & 100 & 1000 & $1-160$ & Linear \\
\hline
\end{tabular}

* Only single tracks were used. 
The above equations ((1) and (2)) present the energy density that is available to heat up and melt the powders for fabricating single $\left(\mathrm{J} / \mathrm{mm}^{2}\right)$ and multiple layers $\left(\mathrm{J} / \mathrm{mm}^{3}\right)$, respectively. The occurrence of various regions in the processing window as well as the resulting microstructure is dependent on the laser energy density, rather than laser power or scanning rate in isolation. Based on the formation quality of the specimens during the SLM process, four regions of behaviour could be defined over the considered range of the laser power and the scanning speed for different magnesium and magnesium alloy powders:

I High energy input zone: In this zone the input energy density is too high under a high laser power for all speeds used. As a result, high temperatures witnessed in the molten pools causes evaporation and ionisation of the powders due to the low boiling point of magnesium $\left(1093{ }^{\circ} \mathrm{C}\right)$. The evaporated powders expand rapidly inducing a strong recoil effect on the molten pool and blowing the liquid and powder away resulting in no track formation. Vaporization of magnesium powders often results in condensation of volatilized materials on the laser window, disrupting the delivery of the laser power [50]. Moreover, effective temperature in the melt pool increased by the high-energy input affects the dynamic viscosity of the overheated liquid magnesium resulting in the instability of the melt pool. Molten magnesium possesses a much lower dynamic viscosity (1.5 Pa-s) than iron (6.93 Pa-s) and titanium (2.2 Pa-s) alloys which are well established in the SLM process. The high energy input during laser processing induces high thermal stresses resulting in reduced viscosity of the melt pool which may lead to deformation of parts [64].

II Low energy input zone: The presence of this zone is influenced by the lowest energy density for all the scanning speeds used combined with relatively low laser power. Using a low laser power and a relatively high scanning speed may not allow the melting temperature of magnesium $\left(650{ }^{\circ} \mathrm{C}\right)$ to be reached which results in partial melting of the powders. The laser energy density is insufficient to generate adequate liquid phase and consequently leads to a poor bond neck between the particulates. Even though there was some fusion between the particles, fragile samples without mechanical strength are obtained and numerous unmolten metal fragments existed on the surface. Samples fabricated using the laser parameters in this zone have many defects such as delamination, brittle fracture and high porosity [67]. Furthermore, a prominent heat-affected zone (HAZ) can be developed during the melting of the tracks. HAZ is developed as a result of partial melting of particles due to radial heat conduction from the centre of the molten pool to the neighbouring powders [8]. If the scanning speed was too fast, more powders, due to the low density and chemical activity of magnesium, were blown up and then oxidized to form a black fog $\mathrm{MgO}$ contaminating the protect-gas chamber [59]. It can be observed from Table 3 that there exists a minimum critical laser energy density above which the SLM of magnesium powders occurred.

III Formation zone: In this zone, acceptable melting of magnesium powders can be achieved in a relatively stable melt pool which yields tracks with good metallurgical bonding. As the formation of a fully molten powder bed is essential in SLM processing to successfully build near full-density parts, sufficient laser energy density is applied to powder materials. Fairly dense structures (i.e., $75 \%-99.5 \%$ ) without obvious macro-defects can be built in a proper range of energy densities which are derivable from the ranges of laser power and scan rates as shown in Table 3 for different magnesium alloy powders. It is believed that the range of energy densities in the formation zone increase the powder bed temperature, while reducing the viscosity of the of the melt pool such that the melt can be spread properly on the formerly processed powder layer, thereby facilitating more efficient densification with solid powdered particles as elucidated by Attar et al. in SLM processing of commercially pure Ti [68] and $\mathrm{Ti}^{-\mathrm{TiB}_{2}}$ composites [69].

IV Balling region: Occurrence of "balling" region is characterised by the agglomeration of a series of ball like particles to form large size melt pools due to insufficient input laser energy density caused by a combination of low laser power, high scanning speed, and large layer thickness [41]. Balling effect is caused due to lack of wetting of the molten pool with the preceding layer which affects the 
coherency of the formed tracks thereby hindering the construction of subsequent layers [70,71]. The balling phenomenon is a complex metallurgical process caused by the instability of the melt pool and the Marangoni effect [51]. Balling is also found to occur at very low scanning speeds owing to the reduction in the surface energy of the liquid at short length scale and long lifetime of the liquid. Occurrence of balling causes a more deteriorated surface resulting from the combination of thermal stresses and weak interlayer bonding between grains and layers. Effects of balling will be discussed further in subsequent sections.

The occurrence of various regions in the processing windows of magnesium and magnesium alloy powders are similar to the regions reported for SLM processing maps studies on aluminium [72], stainless steel [73], gold [74], and iron powders [67].

Table 3. Reported laser energy densities and relative density of SLMed magnesium-based alloys.

\begin{tabular}{ccc}
\hline Materials System & Specific Laser Energy Densities in the Formation Zone & Relative Density (\%) \\
\hline $\mathrm{Mg}[56,57]^{*}$ & $1.27 \times 10^{3}-7.84 \times 10^{3} \mathrm{~J} / \mathrm{mm}^{2}$ (continuous wave irradiation) & - \\
$\mathrm{Mg}[59]$ & $1.13 \times 10^{6}-9.8 \times 10^{6} \mathrm{~J} / \mathrm{mm}^{2}$ (pulsed wave irradiation) & $95.3-96.1$ \\
$\mathrm{Mg}-9 \mathrm{Al}[60]$ & $200-300 \mathrm{~J} / \mathrm{mm}^{3}$ & $74.5-82$ \\
$\mathrm{AZ} 91 \mathrm{D}[61]$ & $93.75-250 \mathrm{~J} / \mathrm{mm}^{3}$ & $73-99.5$ \\
$\mathrm{ZK} 60[62]$ & $83-167 \mathrm{~J} / \mathrm{mm}^{3}$ & $82.25-94.05$ \\
ZK60 [49] & $138-416 \mathrm{~J} / \mathrm{mm}^{3}$ & $72.8-97.4$ \\
\hline
\end{tabular}

* Only single tracks were used.

\subsection{Effects of Laser Processing Parameters on the Processing and Densification of Metal Powders}

Laser processing parameters such as laser power, scanning speed, hatch spacing, and layer thickness have significant impacts on the resulting relative density of SLM-produced samples [75]. Therefore, it is important to understand the effects of laser processing parameters during the building process and obtain suitable combination of these parameters to successfully build near fully density parts. Also, the range of suitable processing parameters obtained is found to be dependent on the chemical composition of the primary alloys [52].

Generally, it has been reported that a minimum laser energy density (or speed below a critical value) is required to produce parts with maximum density [76,77]. Zhang et al. [60] studied the influence of laser energy densities on the densification of $\mathrm{Mg}-9 \% \mathrm{Al}$ alloy parts by setting the laser power and laser scan speed using a continuous wave Nd:YAG laser. It was observed that the increase in laser energy density from $7.5 \mathrm{~J} / \mathrm{mm}^{2}$ to $15 \mathrm{~J} / \mathrm{mm}^{2}$ resulted in improved relative density of the melted samples from $74.5 \%$ to $82 \%$. At lower laser energy densities (higher speeds), there is a significant porosity caused by incomplete melting leading to formation of discontinuous scanning tracks with large sized balls. With increase in laser energy density, better melting of the powders was achieved enabling more liquid phase to flow and infiltrate the voids between the particles and consequently, the pores dispersed and diminished to form a relatively smooth surface with increased density. Maximum densification was achieved under a lower laser power input of $15 \mathrm{~W}$ and a scanning speed of $0.02 \mathrm{~m} / \mathrm{s}$. However, further increment in the laser energy density to $20 \mathrm{~J} / \mathrm{mm}^{2}$ led to a reduction in relative density to $76.1 \%$. Though a sufficient amount of liquid phase was generated at higher laser powers, reduced scan speed causes reduction in the surface energy of the liquid at short length scale causing spheroidisation and breakdown in the melt pool [67]. Further. They concluded that a critical scanning speed of $0.02 \mathrm{~m} / \mathrm{s}$ was required to ensure complete melting of the powders without evaporation and a sound part was not obtained above a speed of $0.04 \mathrm{~m} / \mathrm{s}$ for all the laser powers used. A similar phenomenon has been reported in SLM-processed commercially pure Ti [68] and Ti-24Nb-4Zr-8Sn alloy [78] wherein it was concluded that, once the powder is fully molten, there was no benefit in increasing the laser energy density further due to occurrence of some detrimental 
phenomena such as balling and dross formation in the melt pool, resulting in a poor surface finish and lower density. The densification level obtained was restricted at $82 \%$ and a narrow processing window was obtained due to limitations in the SLM system as operating at a laser power beyond $20 \mathrm{~W}$, caused severe evaporation and subsequent oxidation of magnesium owing to its low boiling point and a low evaporation heat $(5.272 \mathrm{~kJ} / \mathrm{kg}$ ) at ambient pressure [64]. The lower densification levels achieved in this study may also be attributed to the irregular shape of magnesium particles used as it affects the flowability of the powder layers. As was postulated by Attar et al. [79] in SLM processing of Ti-TiB composite powders, usage of non-spherical shaped powder particles negatively influences the uniform deposition of powders, as powders with irregular shape may not flow easily and tend to interlock mechanically and entangle with each other, causing an obstruction in powder flow, consequently leading to the formation of porosities. It is also worth noting that, though SLM is normally processed based on the complete melting mechanism, application of lower laser energy densities can lead to partial melting of the metal powder surface [80]. These surface-melted powders join together due to the presence of liquid metal at the particle interfaces, leaving some interparticle residual porosity. Thus, the partial melting mechanism, wherein complete melting of the powder is avoided, can be effectively used to produce complex shaped porous structures [80]. Partial melting of the powder surface could also lead to formation of partially molten zones within each particle as a result of different melting temperatures of the phases present in magnesium alloys, affecting the microstructure and mechanical properties of SLM processed samples. Comparisons can be drawn to selective laser surface melting (SLSM) process, wherein application of lower laser energy input leads to melting of just the secondary phases without altering the properties of the $\mathrm{Mg} \alpha$-matrix, causing changes in the phase morphology and distribution [81].

Wei et al. [61] investigated the role of SLM laser processing parameters on the formability and densification behaviour of AZ91D alloy to optimize the processing window to obtain parts with higher density and lower porosity. The results are extracted from the published graphs to the best possible accuracy and are reported in Table 4, which shows the effect of variation in scanning speed and hatch spacing on the relative densities of the AZ91D parts formed. It was observed that the relative densities of the parts decreased with increase in both the scanning speed and hatch spacings. At a constant laser power $(p=200 \mathrm{~W})$, decreasing the scanning speed caused a longer dwelling time of the laser beam on the surface of the molten pool, thereby boosting the laser energy density delivered to the powder bed resulting in better densification [82]. Hatch spacing which is also called "scan spacing" is another important parameter that determines the degree of overlap of the laser spot when a new laser line scans over the previously scanned line. The hatch spacing is usually chosen in such a way that it varies between the half width and the full width of melt pool to ensure good bonding of the adjacent tracks [28]. Decreasing the hatch spacing increased the part's density as flowing and spreading of the liquid was increased when the scan lines were brought closer to one another. Also, when the hatch spacing more than the spot size of the laser beam $(100 \mu \mathrm{m})$ was chosen, overlapping was found to reduce as adjacent melt lines did not fuse together completely resulting in increased porosity. Maximum densification of $99.52 \%$ was achieved under a lower scanning speed of $0.33 \mathrm{~m} / \mathrm{s}$ and a hatch spacing of $90 \mu \mathrm{m}$. Energy density of $166.7 \mathrm{~J} / \mathrm{mm}^{3}$ was sufficient to break up any surface oxide layers formed to produce almost fully dense ( $>99.5 \%$ ) AZ91D parts. Near full densification levels achieved in this study can also be attributed to the strict control of concentrations of both $\mathrm{H}_{2} \mathrm{O}$ and $\mathrm{O}_{2}$ below $50 \mathrm{ppm}$ in the build chamber, as no peaks corresponding to $\mathrm{MgO}$ and $\mathrm{Al}_{2} \mathrm{O}_{3}$ were found in the XRD patterns of the SLMed sample built at different energy inputs (Figure 4). Similar results were observed for ZK60 alloys [62], when the effect of scanning speed on part density was investigated with laser power, layer thickness, hatch spacing and laser spot size held at constant values of $200 \mathrm{~W}$, $20 \mu \mathrm{m}, 80 \mu \mathrm{m}$, and $150 \mu \mathrm{m}$, respectively. When the scanning speed was increased from $100 \mathrm{~mm} / \mathrm{s}$ to $900 \mathrm{~mm} / \mathrm{s}$, it was observed that relative density of the part peaked with a value of $94.05 \%$ at $300 \mathrm{~mm} / \mathrm{s}$. At $100 \mathrm{~mm} / \mathrm{s}$, severe vaporization and burning out of the metal powders was observed, leaving an ablated pit on the substrate surface, resulting in termination of the process. At scanning speeds higher 
than $500 \mathrm{~mm} / \mathrm{s}$, powder particles were not melted completely and caused voids between the unmelted powders, resulting in a sharp drop in the relative density of the sample to $82.25 \%$.

Table 4. Relative densities of AZ91 parts formed with varying scanning speed and hatch spacings at laser power $=200 \mathrm{~W}$.

\begin{tabular}{ccccc}
\hline \multirow{2}{*}{ Scanning Speed $(\mathbf{m m} / \mathbf{s})$} & \multicolumn{4}{c}{ Relative Density (\%) at Different Hatch Spacings } \\
\cline { 2 - 5 } & $\mathbf{7 0} \boldsymbol{\mu \mathbf { m }}$ & $\mathbf{9 0} \boldsymbol{\mu \mathbf { m }}$ & $\mathbf{1 1 0} \boldsymbol{\mu \mathbf { m }}$ & $\mathbf{1 3 0} \boldsymbol{\mu \mathbf { m }}$ \\
\hline 333 & 99.4 & 99.5 & 99.2 & 98.8 \\
500 & 99.2 & 99.3 & 99 & 98.4 \\
667 & 99.1 & 98.8 & 93.5 & 89.1 \\
833 & 97.4 & 95.9 & 84.4 & 77.2 \\
1000 & 91.8 & 89 & 76.5 & 73.4 \\
\hline
\end{tabular}

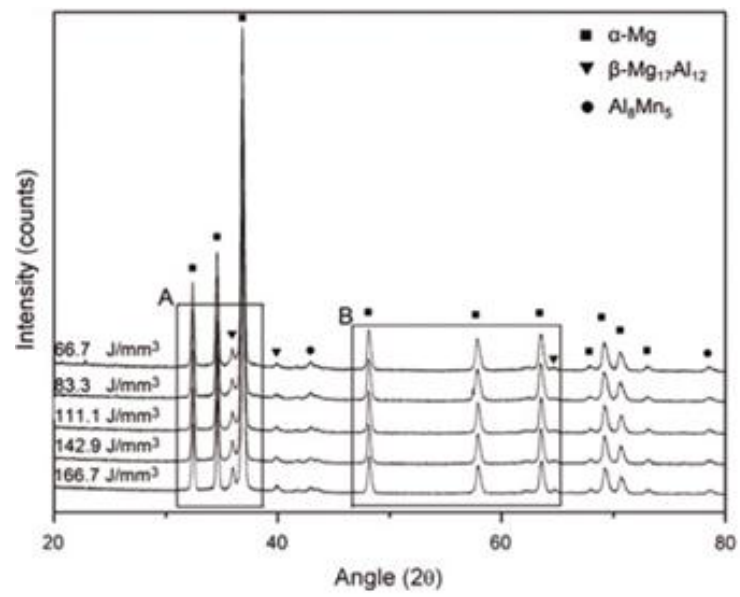

Figure 4. X-ray diffraction (XRD) patterns of the SLMed AZ91D samples fabricated at different laser energy densities indicating absence of any surface oxide films [61].

Layer thickness is another important parameter that has a significant impact on the porosity and layer bonding in the fabricated parts affecting the tensile strength, hardness and dimensional accuracies in the direction of the build [83]. For instance, a higher powder layer thickness will result in less fusion between the particles because the same amount of energy has to be radiated to a greater amount of material as compared to a lower layer thickness. Consequently, less dense parts with more pores and voids will be formed as the laser energy density penetrating the powder bed will be insufficient to completely melt the powder particles. Therefore, an optimum layer thickness must be established to achieve finer resolution and allow for good connectivity between the powder layers with lesser degree of spheroidisation leading to formation of denser parts. Minimum layer thickness can help in improving the quality of the metallurgical bond between successive layers as it helps increasing the penetration depth of the molten pools resulting in multiple remelting of the previously deposited layer and improving the wetting characteristics [61]. Layer thickness also has a close inverse relationship with the total processing time and determines the amount of energy required to melt a layer of powder. The effect of layer thickness on the dimensional and mechanical features of the fabricated tracks from magnesium powder, such as melting depth, melting width, oxidation, elastic modulus, and nanohardness was studied by Savalani et al. [58]. In their study, pulsed mode Nd:YAG laser with a wavelength of $1.06 \mu \mathrm{m}$, spot size of $270 \mu \mathrm{m}$, pulse duration of $20 \mathrm{~ns}$ and a maximum power of $30 \mathrm{~W}$ was used to process the magnesium powder. Scanning speeds were adjusted between 10 and $200 \mathrm{~mm} / \mathrm{s}$ while the layer thickness varied from 150 to $300 \mu \mathrm{m}$. The results demonstrated that there exists a critical value of layer thickness beyond which successful remelting of the previously processed layers was not possible leading to formation of irregular and disrupted surfaces, which was $250 \mu \mathrm{m}$ in 
that study. Flatter surfaces without any surface defects were obtained at a lower layer thickness values of 150-250 $\mu \mathrm{m}$ as seen in Figure 5. Also, no heat affected zone was observed at lower layer thickness values. Since the amount of material to be melted is significantly less, heat conducted in the molten pool has sufficient energy to completely melt the neighbouring particles as opposed to being partially melted. However, lowering the layer thickness below minimal permissible level for a powder system can create problems in spreading homogenous layers of fresh powder [84]. In general, densification is improved with the increase in laser power and decrease in the scan speed, layer thickness and hatch spacing. Similar trends in the densification behaviour is also found to be true for other materials such as Al-12Si [84], Ni-alloy-Cu and Fe-Cu [85].

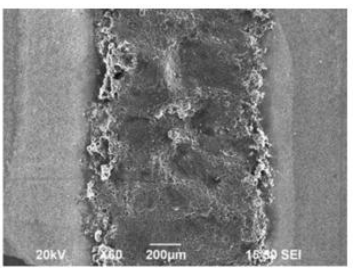

(a)

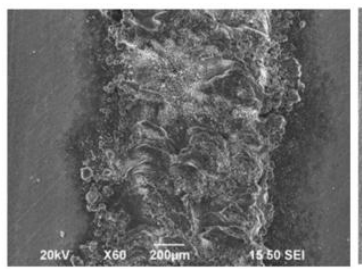

(b)

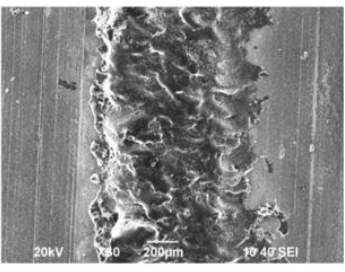

(c)

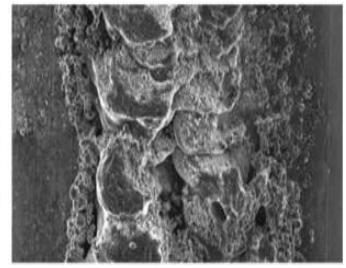

(d)

Figure 5. Effect of variation in layer thickness on the microstructure of laser melted magnesium powder at laser power of $17.7 \mathrm{~W}$, scan rates of $1 \mathrm{~mm} / \mathrm{s}$ : (a) $150 \mu \mathrm{m}$; (b) $200 \mu \mathrm{m}$; (c) $250 \mu \mathrm{m}$ and (d) $300 \mu \mathrm{m}$ [58].

\subsection{Effects of Powder Properties on the SLM Densification Mechanism}

The characteristics and quality of the powder have a strong influence on the process stability and in determining the resulting materials properties. The quality of the powder is determined by size, shape, surface morphology, composition, and amount of internal porosity. The quality of powder also determines physical variables, such as flowability (how well a powder flows) and apparent density (how well a powder packs) [86]. Powder morphology is one important factor in SLM affecting the processing conditions such as flowability, packing of the powders, and nature of heat transfer as well as being a crucial factor in defining the layer thickness and surface roughness during the SLM process [79]. High build rates and part accuracy can be achieved in SLM by employing spherical particles rather than irregular particles as they contribute towards improved flowability of the powders [87]. The powder particles used should be free of defects such as satellites and inter-agglomerate pores, because the presence of such defects can cause lack of fusion between the particles affecting the densification behaviour. The distribution of the powder particle sizes also affects the flowability of the powders as fine powders with a narrow particle size distribution tend to agglomerate and coarse particles with a broader particle size distribution tend to segregate leading to process instabilities [88]. The fraction of smaller particles should be as small as possible to avoid inhomogeneous distribution of the powder over the build platform as friction among the particles increases with decrease in the particle size $[29,59]$. A wider particle size distribution (more fine particles) in SLM of stainless steel 316 L was observed to result in high density ( $>99 \%$ ) across a wider range of process parameters (beam diameter, beam speed) than powder with a smaller particle size distribution [89]. It should be also noted that, powders of different size behave differently during laser processing. Higher size powders melt slower than smaller size. Therefore, in case of wider size distribution, more attention is required for optimizing the process parameters to avoid partial melting of the metal powder surface leading to inter particle residual porosities [90]. Although, higher density parts with better surface finish can be built with lower laser energy density for the finer particles than the coarser particles, they can be easily blown away by the gas flow in the shielding chamber and adhere on the scanning surface impeding the deposition of a thin layer of powder critical to the SLM process [59]. Also, owing to the low density of magnesium particles, very strong interparticle cohesion may take place due to Van der Waals forces affecting the flowability of the powders. It has been shown in some studies that powders with a narrow range of 
particle size and spherical shape can contribute towards improvement of the thermal conductivity of the powder bed resulting in increased density of the SLM processed part [89,91]. A study by $\mathrm{Hu}$ et al. [59] suggests that smaller magnesium powders with a mesh size of $400\left(D_{50}=25.85 \mu \mathrm{m}\right)$ require a lower laser energy input than powders with a mesh size of $250\left(D_{50}=43.32 \mu \mathrm{m}\right)$ to be melted. Similar observations were made during SLM processing of 316 stainless steel powders, wherein powders with $D_{50}$ of $15 \mu \mathrm{m}$ and $28 \mu \mathrm{m}$ required a lower laser energy input to achieve $99 \%$ density than powders with $D_{50}$ of $38 \mu \mathrm{m}$ [92]. However, severe oxidation and balling phenomena were observed for the parts made with finer particles as the melt pool temperature was observed to be higher than that of coarser particles for the same energy input. Further, Hu et al. observed the appearance of small grooves parallel to the spreading direction at the starting edge of specimen fabricated with 400 mesh size powder during the spreading process as shown in Figure 6. At, the starting edge of the specimen, as the scan speed increased from zero to $100 \mathrm{~mm} / \mathrm{s}$, longer interaction time between powder and the laser beam caused the molten pool to exist for a long time resulting in absorption of powder from the heat affected zone. As a result, grooves near the protuberance edge are formed due to insufficient powder availability. Furthermore, no grooves were formed in the case of coarser particles as they cannot be absorbed by the melting pool as easily as the finer particles. However, the effects of powder size or size distribution on the processing maps of different magnesium alloys are still unclear as they have yet to be investigated independently.

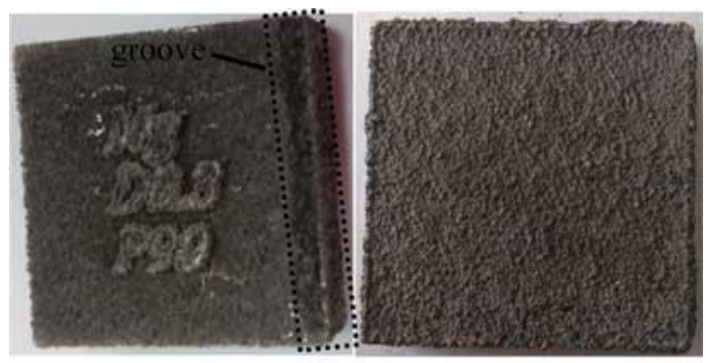

(a)

(b)

Figure 6. Macro-morphologies of specimens fabricated using magnesium powders with granularity of 400 mesh (a) and 250 mesh (b) [59].

The effectiveness of SLM processing has been found to be a function of physical properties of the material (Table 5) such as low absorptivity to the laser beam, low boiling point elements, high thermal conductivity, high co-efficient of thermal expansion, tendency to form low melting point eutectic phases, and low viscosity [52]. One of the integral aspects of SLM is the direct interaction of the powders with a laser beam and the absorption of energy by the powder. The absorptance, defined as the ratio of the absorbed radiation to the incident radiation, affects the energy efficiency of the SLM process. Determining the way energy is absorbed is essential to the thermal development since it allows for the determination of a suitable processing window, free of superheating and evaporation due to excessive laser energy input or a non-response of powder due to an insufficient laser energy input [93]. Initially, incident photons are absorbed at the outer surface of the particles in a narrow layer determined by the bulk properties of the material, leading to an increase in the temperature of the particle surfaces during interaction. Until a local steady state of temperature within the powder is reached, the heat flow will be from the surface to the centre of the particles after which the thermal development takes place through heat transfer determined by the surrounding powder properties [36]. This local no-uniformity in the absorptance characteristics of powders can lead to selective area vaporisation during the interaction between laser and powder particles [36]. Magnesium is highly reflective of the laser energies in the infrared region, having an absorptivity of $8 \%-20 \%$ for a Nd:YAG laser beam with a wavelength of $1.06 \mu \mathrm{m}$ and an absorptivity of $\sim 3 \%$ for a $\mathrm{CO}_{2}$ laser beam with a wavelength of $10.6 \mu \mathrm{m}$ at room temperature [94]. In comparison to the absorptance of bulk materials with smooth 
surfaces, powder materials have significantly higher absorptance regardless of the wavelength of irradiation. For example, at $\lambda=1.06 \mu \mathrm{m}$, the absorptance of Ti powder was observed to be $77 \%$, which is nearly 2.5 times greater than for Ti bulk material, which was just $30 \%$ [36,95]. Although powder materials will have significantly higher absorptance in comparison to bulk materials owing to multiple absorption and reflections in the powder bed, higher than expected laser energies are required to overcome issues such as strong evaporation and reflection of the laser radiation [95]. Also, temperature gradients likely to be formed during the use of overlapping scan tracks caused by difference in the absorptivity of already melted magnesium and the neighbouring powder, may lead to balling. SLM processing of metal powders was reported to be significantly better with the Nd:YAG laser compared to $\mathrm{CO}_{2}$ laser due to its shorter wavelength, which in turn reduced the threshold irradiance required for melting of powders at equivalent penetration depth and scanning speed. Also, a Nd:YAG laser beam produces a slightly larger and more stable scan track than a $\mathrm{CO}_{2}$ laser beam during SLM processing [96]. However, it is noteworthy that the absorptivity of magnesium oxide $(\mathrm{MgO})$ for Nd:YAG laser beam is $\sim 20 \%$ whereas it has an energy absorptivity of $93 \%-98 \%$ for a $\mathrm{CO}_{2}$ laser beam implying that $\mathrm{MgO}$ surface layers on melted parts can effectively increase the absorptivity of laser beams [97]. Therefore, it would be an interesting and worthwhile task to investigate if application of a $\mathrm{CO}_{2}$ laser beam can melt or even evaporate the oxides present in the molten pool owing to enhanced energy absorption, thereby reducing the oxide inclusions in fabricated parts.

Table 5. Properties of pure and alloyed magnesium at its melting point [94].

\begin{tabular}{cc}
\hline Properties (Unit) & Pure Mg \\
\hline Ionisation energy $(\mathrm{Ev})$ & 7.6 \\
Specific heat $(\mathrm{J} / \mathrm{kg} \cdot \mathrm{K}))$ & 1360 \\
Specific heat of fusion $(\mathrm{J} / \mathrm{kg})$ & $3.7 \times 10^{5}$ \\
Melting point $(\mathrm{K})$ & 650 \\
Boiling point $(\mathrm{K})$ & 1090 \\
Viscosity $(\mathrm{Pa}-\mathrm{s})$ & 0.00125 \\
Surface tension $(\mathrm{N} / \mathrm{m})$ & 0.559 \\
Thermal conductivity $(\mathrm{W} /(\mathrm{m} \cdot \mathrm{K}))$ & 78 \\
Thermal diffusivity $\left(\mathrm{M}^{2} / \mathrm{s}\right)$ & $3.73 \times 10^{-5}$ \\
Expansion co-efficient $(1 / \mathrm{K})$ & $25 \times 10^{-6}$ \\
Density $\left(\mathrm{kg} / \mathrm{m}^{3}\right)$ & 1590 \\
Elastic modulus $\left(\mathrm{N} / \mathrm{m}^{3}\right)$ & $4.47 \times 10^{10}$ \\
Vapour pressure $(\mathrm{Pa})$ & 360 \\
\hline
\end{tabular}

Magnesium alloys also possess very high thermal conductivity in addition to high reflectivity. However, deposited powders have relatively poor thermal conductivity and can be considered thermally insulating compared to the solid part of the substrate [86]. As heat is applied, it flows more slowly through the powder, which can lead to overheating of the melt surface located, impacting the size of the melt pool formed and causing density differences between the solid and the powder [98]. Meanwhile, due to high reflectivity and high thermal conductivity of magnesium powder, the SLM process is difficult to control compared with producing other metal powders such as stainless steels or titanium alloys. Also, more laser energy is required to melt the magnesium powders than for materials with lower conductivity.

During SLM processing of Mg-9\%Al powders, Zhang et al. [60], witnessed formation of cauliflower like grains with interconnected pores on the surface of the metal as shown in Figure 7 caused by a metal evaporation-solidification process. Though the majority of the laser energy was reflected because of low absorptivity of both magnesium and aluminium, adequate amount of $\mathrm{Mg}$-Al powder could be melted and a molten pool was formed even at lower energy densities. Due to differences in the thermal properties, the molten pool would absorb much more laser energy than the surrounding powder layer, leading to increase in the molten pool temperature beyond the boiling point of magnesium $\left(1093^{\circ} \mathrm{C}\right)$. Subsequently, an increase in vapour pressure of magnesium from $0.36 \mathrm{KPa}$ at its melting point to $51 \mathrm{KPa}$ at its boiling point led to faster evaporation of the powders and the surface 
of the molten pool was covered by the melt vapour. Further, the magnesium vapours solidified and deposited on the surface of the metal causing formation of cauliflower like grains.

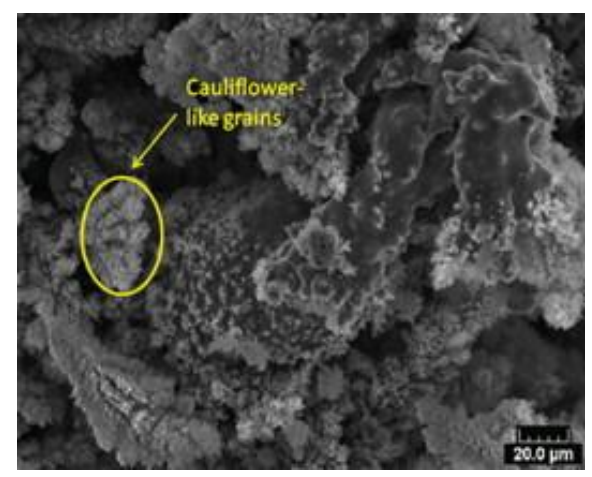

Figure 7. Cauliflower like grains observed during SLM processing of Mg-9\%Al powders [60].

As higher energy input is required to obtain parts with higher density, development of a suitable processing window at higher laser energy densities becomes challenging due to minimal difference between melting and vaporization temperatures of magnesium. However, this problem was overcome by working in an overpressure process chamber having an absolute pressure of $0.3 \mathrm{MPa}$, which increased the boiling point of magnesium by $127^{\circ} \mathrm{C}$ to $1220^{\circ} \mathrm{C}$ allowing for a wider range of laser power and scanning speed to be applied [64]. In contrast to the effect of laser processing parameters, little work has been performed to study the influence of powder properties of magnesium on formation and densification of SLM processed parts. Much more work, therefore is needed to systematically investigate the characteristics of different magnesium alloy powders on the development of a processing window to build fully dense parts.

\section{Microstructure}

Transient cooling patterns employed in SLM dictate the microstructures formed in a deposited layer, due to the rapid and directional solidification resulting in finer microstructures. SLM possesses the capability to control grain sizes and shapes, phase percentages, and phase compositions by manipulation of process parameters as per the design requirements to fabricate parts with tailored mechanical properties. The microstructural characteristics of the consolidated materials fabricated by SLM are strongly sensitive to their thermal history during the build, which may include high heating/cooling rates, significant temperature gradients, bulk temperature rises, and more. The resulting microstructures, which are very fine and far from equilibrium are a consequence of very high solidification rates observed in the SLM process, ranging between $10^{6}$ and $10^{11}{ }^{\circ} \mathrm{C} / \mathrm{s}$ [96]. Since many process variables/parameters impact the thermal history, predicting the microstructural features of SLM parts, and the degree of their dependence on the process parameters, is still a major challenge. However, overcoming this challenge is vital for establishing the effective control mechanisms for fabricating SLM parts with superior mechanical properties. Various authors have investigated the effects of certain parameters on the microstructural characteristics and material properties of SLMed magnesium parts [58-65]. However, it is still unclear how to apply these findings to fabricate complex parts with various shapes since their microstructures will have a unique dependence on thermal history. The solidified microstructure obtained when the SLM processing parameters are varied is dependent on: local solidification rates within the melt pool, the ratio of cooling rate to thermal gradient, $R$, and the temperature gradient at the solid-liquid interface, G. Two critical solidification parameters are the ratio, $G / R$, which affects the solid-liquid interface shape controlling the type of microstructure, and the cooling rate, $G \times R$, which affects the undercooling controlling the scale of microstructure $[99,100]$. Different $G$ and $R$ values may result in three major structure morphologies within SLM parts: columnar (elongated grain morphology), columnar-plus-equiaxed, and equiaxed 
(isotropic grain morphology). It has been found that a higher solidification rate promotes the transition from columnar to equiaxed grain morphologies [101] and that increasing the cooling rate, $G \times R$, leads to a finer microstructure. The tendency to form a columnar structure increases by increasing the ratio $G / R$, while decreasing $G / R$ is favourable for equiaxed structures [99].

Microstructural features along with resulting properties observed for different SLMed magnesium alloy powders are compiled and tabulated for ease of comparison in Table 6. Conventionally cast magnesium alloys are generally characterized by a coarse microstructure consisting of primary $\alpha-\mathrm{Mg}$ and lamellar eutectic ( $\alpha-\mathrm{Mg}+$ intermetallic) phases with an average grain size in the range of $50-150 \mu \mathrm{m}$. However, rapid cooling rates associated along with epitaxial solidification in the SLM process, results in a highly refined microstructure in magnesium alloys with grain sizes of $\alpha$-Mg matrix in the range of 1-20 $\mu \mathrm{m}$ and often favour the formation of partially or fully divorced eutectic (separation of eutectic phases) homogenously distributed along the grain boundaries of dendritic/columnar primary $\alpha-\mathrm{Mg}$ (Figure 8) [49,61]. SLM, being a non-equilibrium process, can extend the solubility of alloying elements in $\mathrm{Mg}$ and obtain single-phase $\mathrm{Mg}$ alloys with wider composition range [61]. SLM also results in compositional and microstructural changes caused by the combined effects of selective evaporation of elements like $\mathrm{Mg}$ and $\mathrm{Zn}$ having very high vapour pressures, and consequent enrichment in the relative content of elements like $\mathrm{Al}$ and $\mathrm{Zr}$ at the surface by "solute capture" phenomenon. In the process of laser rapid melting, very high temperature gradients generated in the melt pool contribute to the formation of a strong Marangoni convection and result in improved homogenous dispersion of alloying elements in the melt pool [62]. Then a subsequent high rate growth of the solid/liquid interface contributes towards "solute capture" phenomenon in $\alpha$-Mg matrix, resulting in larger amounts of solute atoms to be captured, extending the solid solution limit of alloying elements in $\alpha-\mathrm{Mg}$ and retarding the nucleation $\beta$-phases $[49,61]$. Such compositional changes can influence the microstructure, mechanical properties, and corrosion behaviour of laser-melted magnesium alloys.
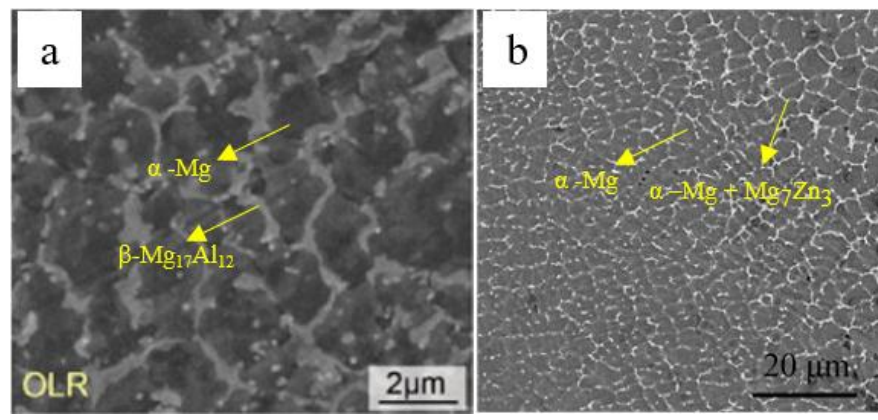

Figure 8. Homogenous distribution of the precipitates formed around the grains during SLM processing of (a) AZ91D alloy at $166.7 \mathrm{~J} / \mathrm{mm}^{3}$ [61] and (b) ZK60 alloy at $600 \mathrm{~J} / \mathrm{mm}^{3}$ [49].

Table 6. Summary of microstructural features and properties achieved for various SLMed magnesium alloy powders.

\begin{tabular}{|c|c|c|c|c|}
\hline $\begin{array}{l}\text { Materials } \\
\text { System }\end{array}$ & General Microstructure/Intermetallic Phase & Hardness (HV) & $\begin{array}{c}\text { Young's } \\
\text { Modulus (GPa) }\end{array}$ & $\begin{array}{c}\text { Surface } \\
\text { Roughness }(\mu \mathrm{m})\end{array}$ \\
\hline $\operatorname{Mg}[56,57] *$ & $\begin{array}{c}\text { Equiaxed } \alpha-\mathrm{Mg} \text { grains, precipitates of } \mathrm{MgO} \\
\text { along grain boundaries }\end{array}$ & 60-97 (from GPa) & $20.8-38.2$ & - \\
\hline $\operatorname{Mg}[58]^{*}$ & - & 66-74 (from GPa) & $29.9-33.1$ & $19-33$ \\
\hline $\mathrm{Mg}$ [59] & - & $44.7-52.4$ & - & $38.6-51.8$ \\
\hline Mg-9Al [60] & Equiaxed $\alpha$-Mg grains $/ \mathrm{Mg}_{17} \mathrm{Al}_{12}, \mathrm{MgO}, \mathrm{Al}_{2} \mathrm{O}_{3}$ & $66-85$ & - & - \\
\hline AZ91D [61] & Equiaxed $\alpha-\mathrm{Mg}$ grains $/ \beta-\mathrm{Mg}_{17} \mathrm{Al}_{12}, \mathrm{Al}_{8} \mathrm{Mn}_{5}$ & $85-100$ & - & - \\
\hline ZK60 [62] & Oriented dendrites $/ \mathrm{MgZn}, \mathrm{Mg}_{7} \mathrm{Zn}_{3}$ & 78 & - & - \\
\hline ZK60 [49] & Dendritic/columnar $\alpha-\mathrm{Mg} ; \mathrm{Mg}_{7} \mathrm{Zn}_{3}$ & $70.1-89.2$ & - & - \\
\hline
\end{tabular}


Microstructures obtained in magnesium alloys with SLM processing are comparable to that achieved by other laser processing techniques such as laser surface melting (LSM) and selective laser surface melting (SLSM). Figure 9 shows the different types of microstructure that can be achieved by laser processing of AZ91D alloy. The commercial die cast AZ91 alloy (Figure 9a) is composed of $\alpha-\mathrm{Mg}$ solid solution and $\beta-\mathrm{Mg}_{17} \mathrm{Al}_{12}$ lamellar eutectic phase distributed along the grain boundaries and its microstructure presents large grains due to the slow cooling rate of the casting process used. Figure $9 b, c$ present the typical appearance of the surface of AZ91 alloy, after modification by LSM and SLSM, respectively. Surface modification by LSM (with a laser power of $600 \mathrm{~W}$ and scanning speed of $45 \mathrm{~mm} / \mathrm{s}$ ) revealed that the microstructure was characterized by very small isolated $\beta-\mathrm{Mg}_{17} \mathrm{Al}_{12}$ phase particles immersed in a continuous supersaturated solution of $\mathrm{Al}$ in $\alpha-\mathrm{Mg}$ matrix, producing a homogeneous and continuous modified layer. SLSM, which is a modification of the LSM process, can be achieved by the application of lower laser energy input $(375 \mathrm{~W}$ and $90 \mathrm{~mm} / \mathrm{s}$ ) causing modification of the $\beta-\mathrm{Mg}_{17} \mathrm{Al}_{12}$ phase only, without any change in the $\alpha-\mathrm{Mg}$ matrix. SLSM also resulting in a eutectic microstructure based on fine plates of $\beta-\mathrm{Mg}_{17} \mathrm{Al}_{12}$ and $\alpha-\mathrm{Mg}$ phase. Modification $\beta$-phase and its surrounding led to a reduction in its hardness and its dispersion, resulting in a more homogenous and continuous material. Figure 9d presents the microstructure of SLMed AZ91 (at a laser energy input of $166.7 \mathrm{~J} / \mathrm{mm}^{3}$ ), which also presents a feature of equiaxed $\alpha$-Mg with fully divorced eutectic $\beta-\mathrm{Mg}_{17} \mathrm{Al}_{12}$ distributed reticularly along the grain boundaries. As the morphology of the eutectic in the hypo eutectic $\mathrm{Mg}-\mathrm{Al}$ alloys depends on the cooling rate [102], change in the form of $\beta$ phase between LSM, SLSM, SLM, and die-castAZ91D is induced by the high cooling rates inherent to laser melting processes.
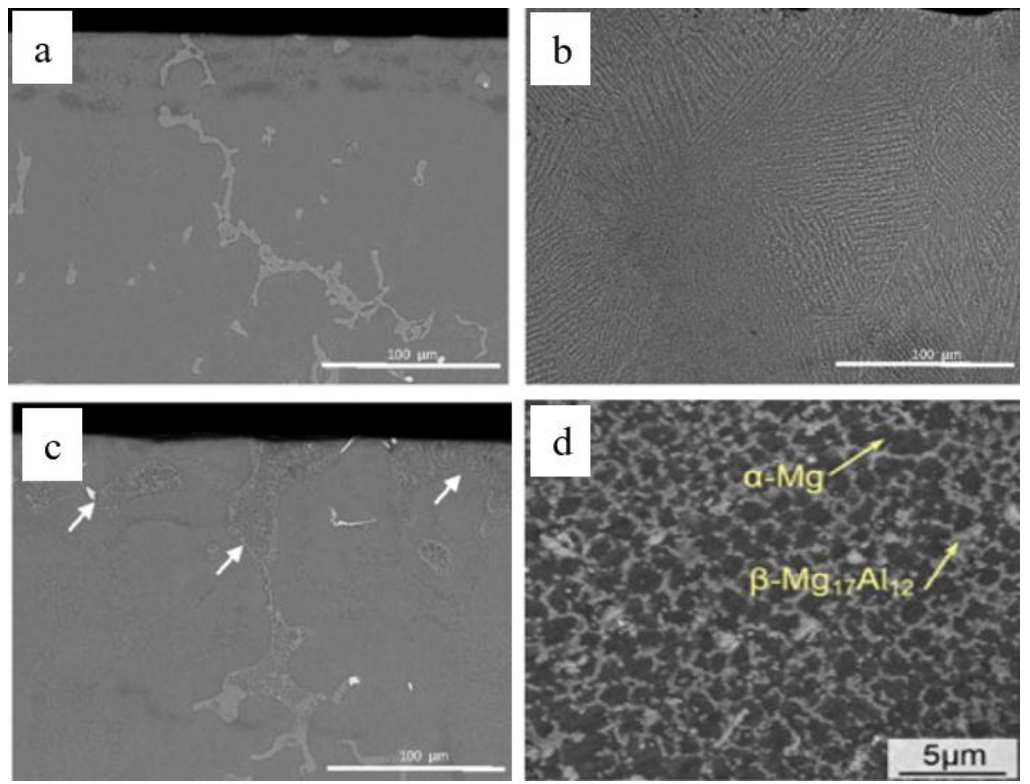

Figure 9. SEM micrographs of the microstructure of AZ91D alloys: (a) as-received alloy [81]; (b) laser surface melting (LSM) [81]; (c) Selective Laser Surface Melting (SLSM) of the $\beta$-phase (arrow marked) [81] and (d) Selective laser melting (SLM) [61].

Under an optical microscope with lower magnifications, the SLM formation features are shown clearly. For example, the curve-like regular laser melted tracks on the cross-section correspond to laser scanning strategy, and the laminar material structure and columnar architecture throughout the vertical section are determined by the specimen building strategy, such as the scanning pattern, hatch spacing, and thickness of layers. The cut ends of melted tracks in the form of a series of arcs on the vertical section which are aligned layer by layer, are induced by the Gauss energy distribution of laser as shown in Figure 10a [61]. The penetration depth of the molten pools was observed to be 
up to $312 \mu \mathrm{m}$, which was approximately eight times the layer thickness $(40 \mu \mathrm{m})$ used in the study for AZ91D alloys (fabricated at a laser energy density of $166.7 \mathrm{~J} / \mathrm{mm}^{3}$ ) indicating that each layer of the as deposited sample undergoes a remelting process more than once. The multiple remelting process plays a significant role in determining the microstructure of SLMed samples as different thermal histories experienced by different layers of the part, led to variation of microstructures along the height direction, as the conduction, convection, and radiation conditions change [61]. The as processed microstructure contains at least two distinct regions: one significantly finer than the other, as shown in Figure 10c,d for AZ91D and ZK60 alloys, respectively. At the edges of the melt pool, the material experiences more cycles of the remelting process caused by both overlapping of the scan lines and creation of subsequent layers to induce relatively lower cooling rates, resulting in localized coarsening of the microstructure. This difference in thermal history between the edges and centre of the melt pool can induce non-uniform distribution of microstructure in the scale of several microns. As can be seen from Figure 10c in the case of AZ91D alloy, the grains on the centre of the scanning tracks (CST) were finer $(\sim 1 \mu \mathrm{m})$ than those near the overlapping edges (OLR) because of the decreasing cooling rate and multiple remelting cycles experienced at the edges of the melt pool. Also, decreasing the temperature gradient inside the melt pool, can lead to occurrence of columnar-to-equiaxed transition towards the centre of the melt pool. As can be seen from Figure 10d, columnar $\alpha$-Mg grains dominate the margin zone of the molten pool whereas $\alpha$-Mg grains in the centre zone of the molten pool presented an equiaxed morphology in the case of ZK60 alloys.
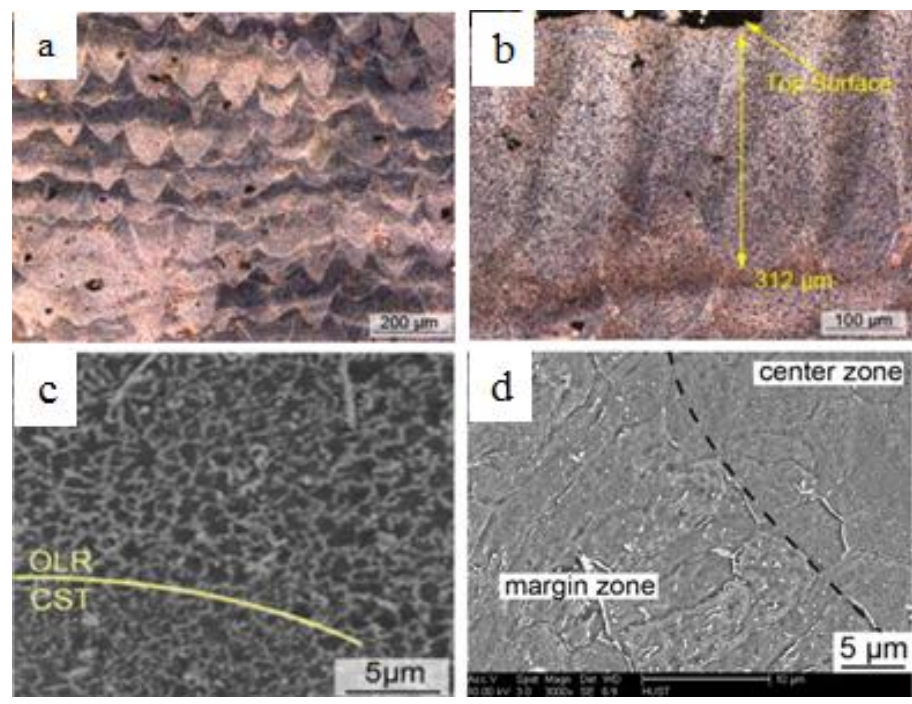

Figure 10. Microstructure of (a-c) AZ91.[61] and (d) ZK60 [62] alloys after selective laser melting: in (a), half-moon shaped melt pools are clearly visible, (b) vertical section indicating multiple remelting of each layer, while (d) shows columnar $\alpha$-Mg grains dominating the margin zone of the molten pool and equiaxed $\alpha-\mathrm{Mg}$ grains in the centre zone of the molten pool.

Microstructural features of SLM processed magnesium alloys can be significantly influenced by the processing parameters used. The combination of higher scanning speeds and lower laser power results in a lower incident energy at the top of the part, typically resulting in finer microstructures due to higher cooling rates. In contrast, lower cooling rates and coarser microstructures can be obtained by decreasing scanning speed and increasing laser power. At relatively lower scanning speeds, prolonged interaction of the laser beam with powders results in the restraining of heat dissipation in the melt pool. As a result, relatively equivalent cooling rates during solidification can be achieved due to larger heat accumulation and thus providing enhanced kinetic qualifications for epitaxial growth of the grains [49]. With the increase of laser energy density, the crystalline structure of magnesium alloys experience successive changes in the order of clustered finer dendrites, uniform equi-axed grains to 
coarsened equi-axed grains. As can be seen from the microstructure of SLM processed ZK60 alloys, extremely fine dendrites $(\sim 2 \mu \mathrm{m})$ which clustered severely together, were observed at a relatively lower laser energy input of $420 \mathrm{~J} / \mathrm{mm}^{3}$ (Figure 11a). The dendrites coarsened to some extent $(\sim 4 \mu \mathrm{m})$ and changed to a column shaped structure with an increase in laser energy input to $500 \mathrm{~J} / \mathrm{mm}^{3}$ (Figure 11b), but still exhibited a disordered distribution. Further increase in the laser energy input to $600 \mathrm{~J} / \mathrm{mm}^{3}$ and $750 \mathrm{~J} / \mathrm{mm}^{3}$ resulted in orderly dispersed, equi-axed grains of $\sim 6 \mu \mathrm{m}$ (Figure 11c) and $\sim 8 \mu \mathrm{m}$ (Figure 11d), respectively. The dendritic crystalline structure was formed through the heterogenous nucleation of $\alpha-\mathrm{Mg}$ and subsequent dendrite growth, whereas, the equi-axed crystalline structure was formed through the homogenous nucleation of $\alpha-\mathrm{Mg}$ and subsequent equi-axed growth of grains [49]. Similar results were observed in the investigation of SLM of Mg-9\%Al alloy powders by Zhang et al. [60] wherein significant grain refinement in the laser-melted region was observed with grain sizes in the range of 10-20 $\mu \mathrm{m}$. The microstructure the $\mathrm{Mg}$ - $\mathrm{Al}$ alloy consisted of equi-axed grains, transformed from dendritic grains under a high temperature gradient. An XRD analysis of the laser-melted samples indicated the presence of phases like $\alpha-\mathrm{Mg}, \mathrm{Mg}_{17} \mathrm{Al}_{12}, \mathrm{MgO}, \mathrm{Al}_{2} \mathrm{O}_{3}$. The $\mathrm{Al}_{2} \mathrm{O}_{3}$ phase was formed as a result of incomplete reaction between $\mathrm{Mg}$ and $\mathrm{Al}$, only under a low energy density input of $93.75 \mathrm{~J} / \mathrm{mm}^{3}$. Further, it was also observed that the content of $\mathrm{Mg}$ decreased in the laser-melted region because of selective evaporation with the increase in laser energy density.

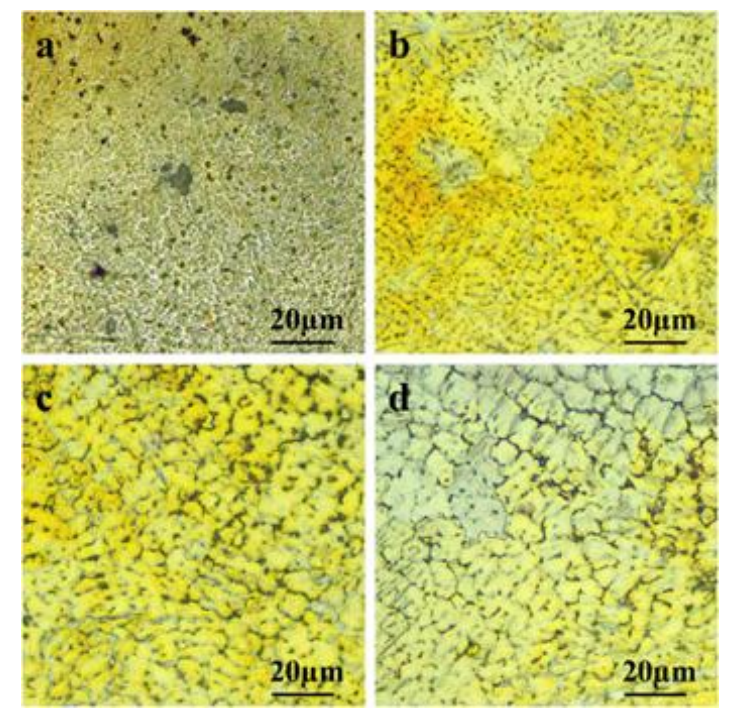

Figure 11. Optical images showing characteristic crystalline structures of laser melted ZK60 prepared at different laser energy densities: (a) $420 \mathrm{~J} / \mathrm{mm}^{3}$; (b) $500 \mathrm{~J} / \mathrm{mm}^{3}$; (c) $600 \mathrm{~J} / \mathrm{mm}^{3}$; (d) $750 \mathrm{~J} / \mathrm{mm}^{3}$ [49].

Reports also indicate that the type and mode of the laser beam used can affect the microstructures formed in SLM processed magnesium as the resultant consolidation mechanism of metallic powders is a function of energy density delivered [39]. $\mathrm{Ng}$ et al. [57] compared microstructures of the tracks formed in SLM processing of magnesium powders, processed under both continuous and pulsed mode of irradiation. Under continuous wave irradiation, laser melting led to the formation of fully recrystallized grains in the melted zones with grain sizes in the range of 2.3-4.87 $\mu \mathrm{m}$ (laser energy densities varied from $1.27 \times 10^{9} \mathrm{~J} / \mathrm{m}^{2}$ to $7.84 \times 10^{9} \mathrm{~J} / \mathrm{m}^{2}$ ). The $\alpha-\mathrm{Mg}$ single phase solidified in the form of equi-axed crystals as seen in Figure 12a. However, in the case of tracks melted under pulsed mode of irradiation, incomplete growth of the $\alpha-\mathrm{Mg}$ phase was observed (Figure 12b). Full growth of $\alpha-\mathrm{Mg}$ was inhibited as the solidification rates achieved under pulsed mode was higher than continuous irradiation. Besides, due to the shorter interaction time in case of pulsed mode, there is insufficient time for the crystals to arrange themselves such that thermodynamic equilibrium prevails at the solid/liquid interface. The average size of grains obtained under pulsed mode were smaller than those obtained in the continuous mode laser melted tracks. Also, smaller laser spot size (50-180 $\mu \mathrm{m})$ 
and layer thickness (typically 20-50 $\mu \mathrm{m}$ ) used in the SLM process when compared to other laser processing technologies such as direct laser deposition (DLD), laser rapid forming (LRF) and laser net shape manufacturing (LNSM) led to the formation of a smaller melting pool, thereby resulting in the formation of a refined microstructure [29]. Normally, layer thickness, alone, has little influence on the microstructure, but its influence is dependent on other parameters, such as laser power, scanning speed, specific energy density, and powder mass flow rate. For example, as the specific laser energy density is lowered, thinner layer thickness will be required, as the energy per unit area to melt the powder is reduced. However, it was observed by Savalani et al. [58] that different layer thicknesses directly affect the oxygen content in the matrix material thereby resulting in phase and microstructural changes. Oxidation occurring during SLM processing of magnesium at different layer thicknesses ranged from approximately 9.1 to 11.7 at \%. The level of oxidation was found to be inversely proportional to the layer thickness, as it decreased from $11.7 \%$ to $9.1 \%$ with the increase in layer thickness from $150 \mu \mathrm{m}$ to $300 \mu \mathrm{m}$.
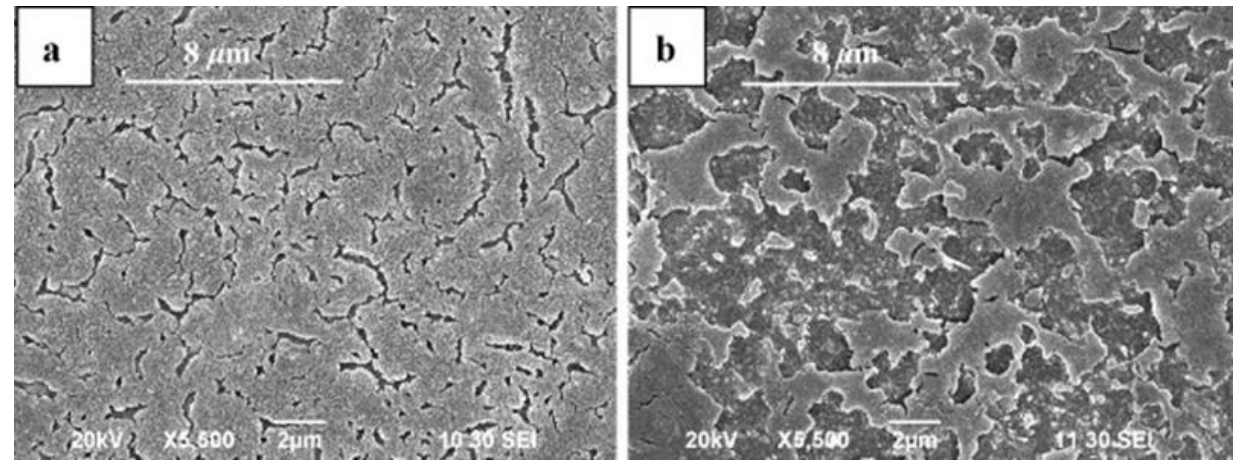

Figure 12. Typical microstructural images of laser-melted magnesium under, (a) continuous wave irradiation at $1.27 \times 10^{9} \mathrm{~J} / \mathrm{m}^{2}$ and $(\mathbf{b})$ pulsed wave irradiation at $1.13 \times 10^{12} \mathrm{~J} / \mathrm{m}^{2}[57]$.

\section{Metallurgical Defects}

\subsection{Oxide Inclusions}

The presence of surface oxide film on the preceding layer impedes interlayer bonding which in turn inhibits the densification mechanism and leads to balling as liquid metals generally do not wet oxide films in the absence of a chemical reaction. In combination with thermal stresses, poor interlayer bonding can also cause delamination of SLM processed parts. Similar to the casting process as pointed out by Campbell [103], oxide may get into the melt pool either via alloying addition into the metal powder during primary processing or air/gas entrapment via surface turbulent flow during SLM processing. Also, as the vaporization of alloying elements in the scan tracks is not uniform while the scan track positions vary with time, rapidly fluctuating scan tracks tend to entrap the shielding gas or even air which may contain traces of oxide particles. Consequently, the surface of the liquid metal in the melt pool then become oxidized to form oxide film as a result of the entrapment of air or shielding gas into the melt pool.

The oxidation of a metal M may be represented by

$$
\mathrm{M}+\mathrm{O}_{2} \rightarrow \mathrm{MO}_{2}
$$

The free energy of formation $\delta G$ of the oxide is given by

$$
\delta G=-R T \ln K
$$


where $R$ is the gas constant, $T$ is the temperature in Kelvin and $K$ is the equilibrium constant given by

$$
K=\left(\mathrm{PO}_{2}\right)^{-1}
$$

where $\mathrm{PO}_{2}$ is the partial pressure of oxygen when reaction (3) is at equilibrium. For magnesium at $700{ }^{\circ} \mathrm{C}$, a $\mathrm{PO}_{2}$ of $10^{-54} \mathrm{~atm}$ or higher will give oxidation of magnesium [104]. Thus, thermodynamically, it should not be possible to prevent oxidation of the magnesium. Since the formation of oxide films cannot be avoided completely, the SLM process must break up these oxides if fully dense parts are to be formed, and this is why SLM fabrication of high density parts requires high laser power. According to Louvis et al. [105], the oxide film on the upper surface of the pool evaporates under a laser beam. Marangoni forces that stir the pool are the most likely mechanism by which these oxide films are disrupted, allowing fusion to the underlying layer. However, the oxides at the sides of the pool remain intact and, thus, create regions of weakness and porosity, as the pool fails to wet the surrounding material. Therefore, further research on the SLM of magnesium should be primarily orientated towards new methods of controlling the oxidation process and disrupting oxide films formed within the components.

It has been shown that significant amounts of oxide are present within the selective laser melted magnesium and tended to form between scan tracks rather than between layers, as shown in Figure 13 . It is also expected that the oxide would form on top of the melt pool, which may retard its spreading and alter the wetting characteristics and result in a porous structure with weak mechanical properties. However, provided that sufficient energy is imparted, this surface oxide will break up and become encapsulated within the melt pool. However, it may then act as a micro crack in the system and, therefore, be detrimental to the final mechanical properties of the product. Just as oxide films are damaging to magnesium alloy castings, so they are to SLM processed parts made in magnesium alloys. However, the potential role of oxide films affecting the densification, mechanical properties, and corrosion behaviour of SLM processed magnesium alloy parts has not been elucidated due to abundance of some defects such as porosity and loss of alloying elements. It is expected that the potential role of oxide films will possibly be highlighted by SLM processing of magnesium alloys in the future, once these defects are eliminated.

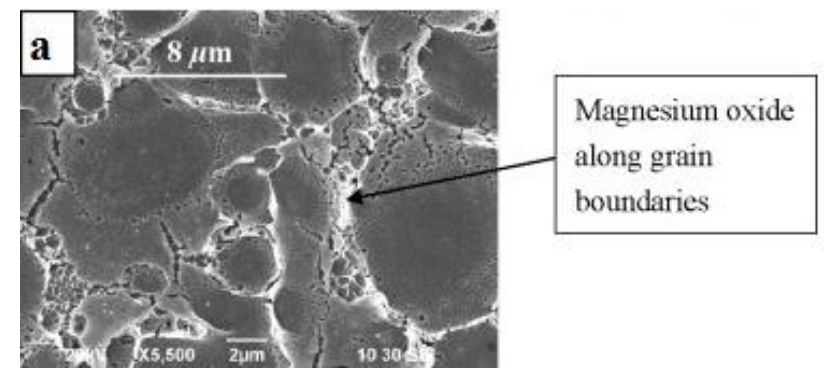

Figure 13. SLMed magnesium track fabricated at a laser energy density of $7.89 \times 10^{3} \mathrm{~J} / \mathrm{mm}^{2}$ [57]

\subsection{Loss of Alloying Elements}

Higher vapour pressure and low boiling points of elements like magnesium and zinc can lead to preferential element vaporization during the interaction between laser and magnesium alloys [94]. It is also well known that the temperatures reached within melt pools during the SLM process are far greater than the boiling temperatures of magnesium, aluminium, or zinc. Thus, the preferential evaporative losses during SLM will consist primarily of zinc and magnesium. Intrinsic vaporization of elements at the melt pool surface during laser processing takes place initially by the transportation of vaporization elements from the bulk to the surface of the molten pool, followed by vaporization of elements at the liquid/vapour interface; then the vaporized species are transported into the surrounding gas phases [106]. Sometimes, because of low diffusivity, the vaporized species are re-condensed and 
deposited back immediately around the laser irradiated zones and are remelted during subsequent scanning to compensate for the initial losses [62]. However, condensation of volatile alloy constituents on the surface of the molten pool to a greater extent can lead to formation of a black coating [107]. During SLM of AZ91D alloys, Wei et al. [61] observed that selective vaporization of magnesium caused an increase in the concentration of aluminium in the molten pool. Increasing the laser energy density from $83.3 \mathrm{~J} / \mathrm{mm}^{3}$ to $166.7 \mathrm{~J} / \mathrm{mm}^{3}$ caused an increase in the content of $\mathrm{Al}$ in $\alpha$-Mg solid solution from $8.31 \mathrm{wt} \%$ to $10.98 \mathrm{wt} \%$ signifying a higher burning loss rate of $\mathrm{Mg}$ atoms. Further, due to the interaction of "solute capture" and element evaporation, the content of the hard-brittle $\beta$-phase and the solubility of solute elements in the $\alpha-\mathrm{Mg}$ matrix increased simultaneously with increasing laser energy inputs. Similar results were observed in case of ZK60 alloys [62], wherein a larger reduction in the content of both $\mathrm{Mg}$ and $\mathrm{Zn}$ was reported at slower scanning speed with subsequent enrichment of $\mathrm{Zr}$ after processing. Also, a higher $\mathrm{Mg}: \mathrm{Zn}$ ratio in the final parts was observed when compared to raw material. Though evaporation during SLM is known to be a problem for aluminium alloys, it did not appear to be so detrimental in the processing of $\mathrm{Mg}-9 \% \mathrm{Al}$ alloys [60]. However, evaporative losses can be more problematic in case of low zinc zirconium alloys wherein evaporation and decline in the content of alloying elements can be detrimental to the mechanical performance and can lead to degradation of functional properties of SLMed sample.

Evaporation of alloying elements taking place at higher laser energy densities during laser melting will affect the stability of the molten pool along with causing a variation in composition and microstructure of the deposited layers [106]. Metal vaporization leads to formation of recoil pressure in the molten pool, which tends to push the liquid away from the melt zone, resulting in formation of a keyhole defect [108]. Formation of key hole defects results in inferior surface quality of the specimen showing varying depths as observed during SLM of ZK60 alloys [62].The depletion of alloying elements leads to a higher degree of porosity in the laser processed parts limiting the level of maximum densification that can be achieved. Composition inhomogeneities resulting from selective evaporation of elements is a function of the vaporization rate and the volume of the molten pool [94]. Thus, careful control and manipulation of SLM process parameters is required to ensure reduction in the occurrence of elemental redistribution and porosity. Loss of high vapour pressure alloying elements can be effectively minimized by regulating the molten pool temperature, which in turn can be achieved by controlling the beam power density distribution in case of continuous wave irradiation and adjusting the pulsing parameters in case of pulsed wave irradiation [52]. Although, high laser energy densities lead to greater evaporative losses, compositional inhomogeneities are most pronounced at low energy density levels due to small size, and the high surface-to-volume ratio, of the molten pool [94]. In order to avoid vaporization of elements during SLM processing of magnesium alloys, it is recommended to employ laser processing parameters combining medium or high power with high scanning speeds and also it is necessary to further understand the mechanism, to investigate the main influencing factors and to build up the quantitative relationship between the vaporization losses and SLM process parameters.

\subsection{Balling}

Balling phenomena are regarded as the typical microstructure occurring on surfaces of SLM-processed parts from a bed of loose powder [39]. Balling is defined as an agglomeration of the particles, occurring where the liquid phase breaks up into a row of spheres to reduce surface energy. As discussed previously, occurrence of "balling" region is characterised by the agglomeration of a series of ball like particles to form large size melt pools due to insufficient input laser energy density caused by a combination of low laser power, high scanning speed, and large layer thickness [41]. The main factor leading to balling is the Gibbs-Marangoni effect, which is the mass transfer along an interface between two fluids due to the surface tension gradient [109]. In terms of temperature association, this phenomenon is also called thermo-capillary convection. During SLM, laser scanning is performed line by line and the laser energy causes melting along a row of powder particles, forming 
a continuous liquid scan track in a cylindrical shape. The diminishing in the surface energy of the liquid track continues until the final equilibrium state through the breaking up of the cylinder into several metallic agglomerates in spherical shape [39]. Three kinds of balling mechanisms have been identified by $\mathrm{Gu}$ et al. $[73,110]$ during SLS processing of $\mathrm{Cu}-30 \mathrm{CuSn}-10 \mathrm{CuP}$ and stainless steel powder. "First line scan balling" is observed when initial tracks on a cold powder bed are scanned, caused by high thermal gradients imposed on the melt. "Shrinkage induced balling" is caused by the capillary instability of the melt pool when higher scanning speeds are used. "Splash-induced balling" with the formation of a large amount of micrometre-scale balls occurs at a high laser power combined with a low scan speed, because of the considerably low viscosity and long lifetime of the liquid.

Figure 14 shows the occurrence of balling phenomenon observed during SLM processing of Mg-9\%Al powders [60], wherein a large amount of micrometer-scaled (diameter of 10-20 $\mu \mathrm{m}$ ) spherical splashes, formed around the sintered surface, can be seen. When relatively higher scanning speeds were applied, laser energy density of the laser input decreased causing a significant shrinkage in inter particle areas, leading to capillary instability of the molten pool. Therefore, due to the reduction in surface energy of the liquid at short length scales, small sized liquid droplets splashed from the liquid surface. Further, balling obstructed the formation of continuous melt lines, forming rough and bead-shaped surfaces. In more severe cases, balling may aggravate in subsequent layers and jam the powder coating mechanism with large metallic beads that extend above the powder bed. The balling effect can be avoided if the stability of the melt pool is improved by reducing the length/width ratio of melt pool and/or increasing contact width, which can be achieved by increasing the laser power or decreasing the scanning speed [111]. According to Li et al. [112], lowering the oxygen level during the process and introducing repeat exposure of laser to break up the oxide films are ways to minimize the occurrence of balling, as balling behaviour during the SLM process is related to the oxidation of metals [112]. In their study regarding SLM processing of Ni and stainless steel powders, it was observed that balling could be reduced significantly by keeping the oxygen level at $0.1 \%$, and by applying a combination high laser power and low scanning speed or applying re-scanning of laser [112]. However, even though the oxygen content in the chamber was kept below $0.2 \%$, Hu et al. [59] observed the occurrence of balling during SLM processing of magnesium, as magnesium being very active is susceptible to oxidation.
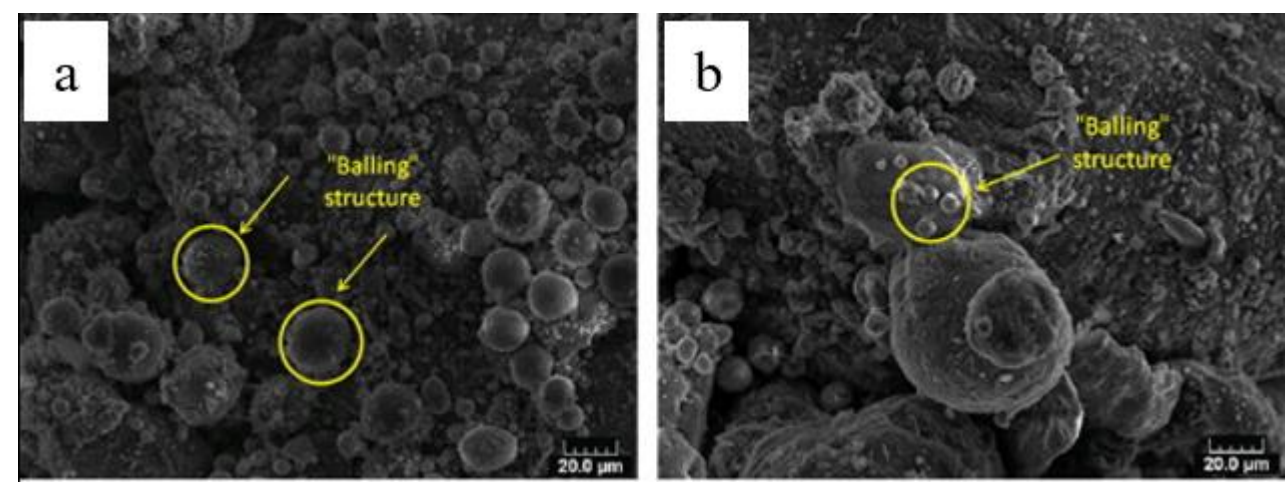

Figure 14. SEM image showing cluster of balls (balling effect) in SLM processed $\mathrm{Mg}-9 \% \mathrm{Al}$ due to non-optimized laser processing parameters [60].

\section{Mechanical Properties}

Properties observed for different SLMed magnesium alloy powders are compiled and shown in Table 6. Figure 15 presents the comparison of hardness and Young's modulus values reported for laser melted parts with conventionally cast and wrought magnesium alloys in literature. SLM of magnesium alloys results in high surface hardness than that of as-cast alloys, as a result of solid solution strengthening effects (because of solute supersaturation with rapid cooling or solute enrichment with 
selective evaporation of elements). The microhardness is found to gradually fluctuate from the centre of the molten pool to the margin zone due to the variations in the microstructure between the two regions. However, the microhardness for deposited samples showed directional independence [61]. According to Mercelis and Kruth [113], residual stresses are not always disadvantageous in SLM fabricated parts because their retention at a reasonable level enhances the part's hardness provided sufficiently high densification without formation of cracks or pores could be achieved. Moreover, the rapid solidification effect imparted on the as-processed parts by the SLM which results in grain refinement of the microstructure is another reason that could be attributed to increased hardness of the SLM fabricated parts. Figure 16 shows the variation of hardness of SLM processed magnesium tracks with different laser energy inputs as measured by $\mathrm{Ng}$ et al. [57]. It is evident that the resulting hardness values can effectively be controlled by adjusting the laser energy densities in the formation zone. The hardness values were found to increase with decrease in the laser energy input. The higher cooling rate induced by low laser energy density resulted in smaller grain sizes, so that the hardness values were mainly related to the grain size in the melted zone. Also, the reported Young's modulus values for various magnesium alloys are in the range of 20-35 GPa, which are close to the corresponding ones of human bones (3-20 GPa), indicating that they can be considered as a potential candidate for biomedical implants [114].

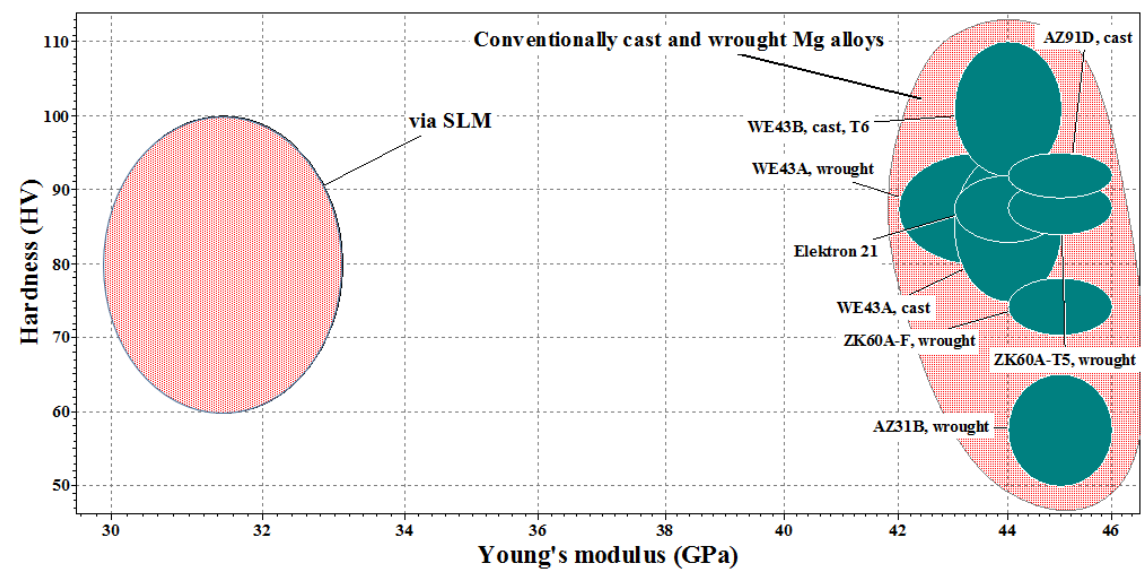

Figure 15. Comparison of hardness and Young's modulus values of SLM processed parts with conventionally cast and wrought magnesium alloys.



Figure 16. Grain size against the microhardness values of single track magnesium samples [56]. 
Figure 17 presents the comparison of tensile properties reported for laser melted parts with conventionally cast and wrought magnesium alloys in the literature. As can be seen from Figure 17, the yield strengths of SLM parts are comparable or superior to those fabricated from cast and wrought materials in most cases. This is generally attributed to the nature of the SLM process, where a very small amount of material is melted at a time and rapid solidification takes place. This results in a more uniform microstructure throughout the part. For alloys, the segregation of the alloying elements takes place on a much smaller scale. The chemical composition is more uniform throughout the part, resulting in higher strength than for cast parts [115]. However, the elongation to failure is typically lower for SLM parts and this could be attributed to micro-porosity and oxide inclusions within the parts - a result of the non-optimized SLM process. Wei et al. [61] investigated the tensile properties of SLM processed AZ91D alloy at different laser energy inputs. It was established that laser energy input had a significant influence on tensile properties as the average ultimate tensile strength and yield strength of the SLMed samples were found to decrease gradually from $296 \mathrm{MPa}$ and $254 \mathrm{MPa}$ at $166.7 \mathrm{~J} / \mathrm{mm}^{3}$ to 274 and $237 \mathrm{MPa}$ at $83.3 \mathrm{~J} / \mathrm{mm}^{3}$. This is as a result of poor relative densities of SLMed samples obtained at lower energy inputs coupled with lower solid solubility of the $\alpha-\mathrm{Mg}$ matrix and a smaller quantity of intermetallic $\beta$ phase induced by lower energy inputs. Analysis of the fracture behaviour of SLM parts showed features of ductile-brittle hybrid fracture. Owing to the layer by layer manufacturing approach, it was observed that the part's building orientation during SLM was found to affect the resultant tensile properties of the part. Specimens deposited in the direction along (e.g., parallel to) the length of the tensile samples (e.g., $X$-direction) typically exhibit higher tensile strength than those with layers deposited perpendicular to their length (e.g., $Y$ or Z-direction) [116]. Although the reasons for this have not been well investigated, it does show that the effects of the building orientation for magnesium alloys is more involved and requires further investigation. Also, performing a hot isostatic pressing (HIP) procedure after SLM can significantly reduce the anisotropic mechanical behaviour of the SLMed parts by reducing manufacturing induced porosity [116].

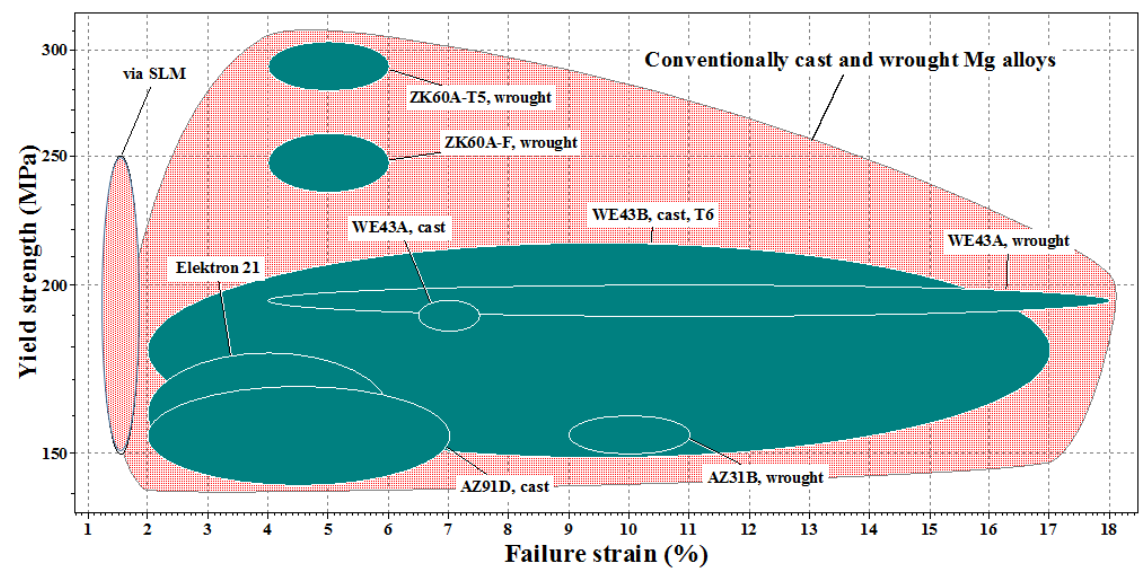

Figure 17. Comparison of tensile properties of SLM processed parts with conventionally cast and wrought magnesium alloys.

\section{Corrosion Behaviour}

Magnesium alloys, generally, reveal a poor corrosion resistance, which is mainly associated with their high chemical activity and the lack of a protective passive oxide film $[117,118]$. This disadvantage has been a major obstacle restricting their further application in automotive, aerospace, and electronics industries. Also, magnesium has a high negative standard electrode potential, which leads to the rapid corrosion of magnesium based alloys in chloride physiological conditions [119]. This has delayed the introduction of magnesium based materials for therapeutic applications to date, as the hydrogen gas produced at a high rate from corrosion cannot be dealt with by the host tissue [18]. 
Additionally, shift in alkaline $\mathrm{pH}$ in the region surrounding the corroding surface is also a concern for biomedical applications [119]. Therefore, development of magnesium alloys with improved corrosion behaviour may help to resolve the current limitations of magnesium alloys for use in the aforementioned industries. Rapid solidification has been identified as an effective method to improve the strength and corrosion resistance of magnesium alloys for structural and corrosive media utilization [40]. Laser melting is one such rapid solidification process involving cooling rates up to $10^{6-8}{ }^{\circ} \mathrm{C} / \mathrm{s}$ and is capable of modifying surface properties as it can homogenize and refine the microstructure, and dissolve secondary phases $[120,121]$. However, so far, little effort has been made to examine the corrosion behaviour of the SLM-produced magnesium parts as most studies on the SLM of magnesium alloy powders have been focussed on the densification and mechanical properties of the SLM-produced samples.

Because of the paucity of literature dealing with corrosion behaviour and its associated mechanism during SLM of magnesium alloys, it would be useful to examine the effect of laser surface melting (LSM) treatment on the corrosion behaviour of magnesium alloys, as corrosion is essentially a surface degradation process. LSM treatment has been effective in improving the corrosion resistance of AZ and AM type of magnesium alloys, such as AZ31, AZ61, AZ91, and AM60 [122-128]. Improved corrosion resistance of these alloys was mainly attributed to the pronounced refinement of $\alpha-\mathrm{Mg}$ grains and uniform redistribution of inter metallic compounds after laser treatment. In the case of magnesium alloys, it has been observed that, grain refinement and homogenization of compositional distribution can decrease the volume fraction of the effective cathodes, thereby limiting the cell action caused by the accumulation of cathodic phases [129]. In addition, the corrosion resistance also increased with the enrichment of aluminium content in the laser-melted zone because of the selective evaporation of magnesium, providing passive characteristics to the melted surface [124]. Enrichment of alloying elements can shift the corrosion potential of $\alpha-\mathrm{Mg}$ to the positive direction, lowering the corrosion susceptibility of $\alpha$-Mg matrix [130]. Furthermore, rapid laser-melting could increase the solid solubility of alloying elements, such as $\mathrm{Mn}, \mathrm{Al}$, and $\mathrm{Cr}$, promoting the formation of more protective and self-healing films and thus limiting the occurrence of local galvanic corrosion [129]. It is expected that insights gained from how LSM treatment can enhance the corrosion resistance of magnesium alloys, could be helpful in understanding the mechanisms associated with corrosion behaviour of SLM processed magnesium alloys.

In a recent study, Shuai et al. [49] investigated the corrosion behaviour of SLM-processed ZK60 alloy by performing immersion tests in Hanks's solution ( $\mathrm{pH} 7.4 \pm 0.1$ ) at $37 \pm 0 .{ }^{\circ} \mathrm{C}$ for $48 \mathrm{~h}$. Hydrogen volume evolution rates observed were in the range of $0.006-0.0019 \mathrm{~mL} \cdot \mathrm{cm}^{-2} \cdot \mathrm{h}^{-1}$ as the laser energy input varied from $420 \mathrm{~J} / \mathrm{mm}^{3}$ to $750 \mathrm{~J} / \mathrm{mm}^{3}$. The lowest hydrogen evolution volume rate of $0.006 \mathrm{~mL} \cdot \mathrm{cm}^{-2} \cdot \mathrm{h}^{-1}$ was observed at a laser energy input of $600 \mathrm{~J} / \mathrm{mm}^{3}$, for which a maximum densification of $97.4 \%$ was achieved. Such low volume release rate of hydrogen achieved, is within the limit of $0.01 \mathrm{~mL} \cdot \mathrm{cm}^{-2} \cdot \mathrm{h}^{-1}$ that can be tolerated by the body without posing any serious threat [131]. SLM processed ZK60 alloy showed significant enhancement in corrosion resistance compared to casted ZK60, which had a hydrogen volume evolution rate of $0.154 \mathrm{~mL} \cdot \mathrm{cm}^{-2} \cdot \mathrm{h}^{-1}(\sim 80$ times higher $)$ during immersion in Hank's solution [132]. However, the outcome from Shuai et al. [49] contradicts the findings from studies carried out by Dai et al. $[133,134]$ who reported that SLM-produced Ti-6Al-4V has an unfavourable corrosion resistance compared to its traditional counterparts. The reported contradiction about the effects of laser melting on the corrosion behaviour of SLM processed metal powders might have been possibly engineered by different mechanisms of microstructure evolution and corrosion reactions, occurring during laser processing of different materials. The exact nature of the corrosion reactions and the associated mechanisms affecting the corrosion behaviour for various metallic powders need to be explored further in future studies.

When ZK60 alloy was soaked in Hank's solution, the following reactions occurred [49]:

$$
\mathrm{Mg} \rightarrow \mathrm{Mg}^{2+}+2 \mathrm{e}^{-}
$$




$$
\begin{gathered}
2 \mathrm{H}_{2} \mathrm{O}+2 \mathrm{e}^{-} \rightarrow \mathrm{H}_{2} \uparrow+2 \mathrm{OH}^{-} \\
\mathrm{Mg}^{2+}+2 \mathrm{OH}^{-} \rightarrow \mathrm{Mg}(\mathrm{OH})_{2}
\end{gathered}
$$

The corrosion of ZK60 in Hank's solution accompanied a release of $\mathrm{H}_{2}$. The reactions were driven by the relative potential difference between the relative anode and cathode. As for the ZK60 alloy, homogenously distributed $\mathrm{Mg}_{7} \mathrm{Zn}_{3}$ secondary phase served as a cathode and formed a galvanic couple with the $\mathrm{Mg}$ matrix resulting in macroscopic homogenous corrosion characteristics. The corrosion was triggered by the dissolution of the $\alpha-\mathrm{Mg}$ matrix adjacent to intermetallic compounds. The enhanced corrosion resistance observed in SLM processed ZK60 alloy can partly be ascribed to the increase in the corrosion potential caused by enrichment of the solid solution of $\mathrm{Zn}$ (caused by increased "solute capture" effect), which possessed a higher corrosion potential $(-0.76 \mathrm{~V})$ than that of $\mathrm{Mg}(-2.34 \mathrm{~V})$. Thus, increase in the corrosion potential of Mg matrix, namely, decrease in the relative potential difference, had a beneficial effect on reducing the relative anodic and cathodic reaction supported by the $\mathrm{Mg}$ alloy. In addition, once the corrosion was initiated, the refined $\mathrm{Mg}_{7} \mathrm{Zn}_{3}$ phases distributed evenly and mainly served as a barrier to impede corrosion process. Similarly, Yang et al., during SLM processing of Mg-Mn alloys [66], observed that corrosion resistance of pure magnesium was enhanced by the addition Mn of up to $2 \mathrm{wt} \%$ during immersion testing carried out in simulated body fluid (SBF) (pH 7.4) at $37^{\circ} \mathrm{C}$ for $48 \mathrm{~h}$. The hydrogen volume evolution observed for Mg-2Mn alloy $\left(0.017 \mathrm{~mL} \cdot \mathrm{cm}^{-2} \cdot \mathrm{h}^{-1}\right)$ was significantly lower than that of pure $\mathrm{Mg}\left(0.068 \mathrm{~mL} \cdot \mathrm{cm}^{-2} \cdot \mathrm{h}^{-1}\right)$. The enhancement of $\mathrm{Mg}$ corrosion resistance was attributed to the increase in corrosion potential and grain refinement caused by the solid solution of Mn. Further, they suggested SLM processed Mg-2Mn alloy as a potential candidate for future bone implants. However, corrosion in body fluids is influenced by various factors such as $\mathrm{pH}$, concentration and types of ions, protein adsorption on orthopedic implant, and influence of the biochemical activities of surrounding tissues $[135,136]$. Therefore, further investigations are still necessary to develop the reliability of SLM processed magnesium parts for biomedical applications.

\section{Potential of SLM to Fabricate Porous Magnesium Structures}

Human bone has a hierarchical structure with three major anatomic cavities of different sizes which are haversian canals $(50 \mu \mathrm{m})$ [137], osteocytic lacunae (few micrometres) [15,138,139], and canaliculi $(<1 \mu \mathrm{m})[140,141]$. Each of the three cavities has a major role in remodelling the processes and mechanical integrity of the bone [14]. A porous structure allows adequate spaces for transportation of nutrients and for growth of living tissues [142]. Especially for metallic orthopaedic applications, by adjusting the porosity levels, the modulus of the materials can be greatly controlled which provides an opportunity to design materials with a modulus closer to that of natural bone thereby mitigating problems related to stress shielding [143]. Metal cellular structures can be classified into structures with stochastic and non-stochastic geometries. Metal stochastic porous structures typically have a random distribution of open or closed voids, whereas metal periodic cellular lattice structures have uniform structures that are generated by repeating a unit cell [144]. Apart from medical fields, metallic cellular/porous structures have also been broadly utilized in the automotive, aerospace, and chemical industries as they possess lower weight, good energy absorption characteristics, and good thermal and acoustic properties $[145,146]$. However, it is difficult to fabricate structures of such complex external shapes and intricate internal architectures by conventional casting and powder metallurgy methods. Although the shape and size of the pores can be adjusted by changing the parameters of these manufacturing processes, only a randomly organized porous structure can be achieved [144]. However, additive manufacturing (AM) technologies can fabricate porous metals with a predefined external shape and internal architecture to match the modulus or stiffness of bone, thereby minimizing or eliminating stress shielding $[147,148]$. Selective laser melting (SLM) offers a significant advantage of producing such very fine and porous structures while at the same time accommodating a variety of shapes that are not only limited to prismatic ones [26]. This makes it the preferred technology for producing metallic scaffolds and implants. Also, Studies on SLM have shown that the internal and 
surface finish of the implants can be tailored to have selectively porous and/or lattice-like structures to promote osseo-integration (bonding between the bones and the implant) in the implants [42]. SLM technology has been used to produce complex porous/cellular structures directly from different engineering materials such as stainless steel [144] and titanium alloys [108,149-151] and therefore has the potential to produce porous structures in magnesium alloys. In a recent study, Jauer et al. [65] were successful in fabricating scaffold-like structures with designed interconnected porosity out of WE43 by means of SLM (Figure 18). However, the processing parameters for fabricating such structures are currently under development and details of research in this area are not available in the open literature.

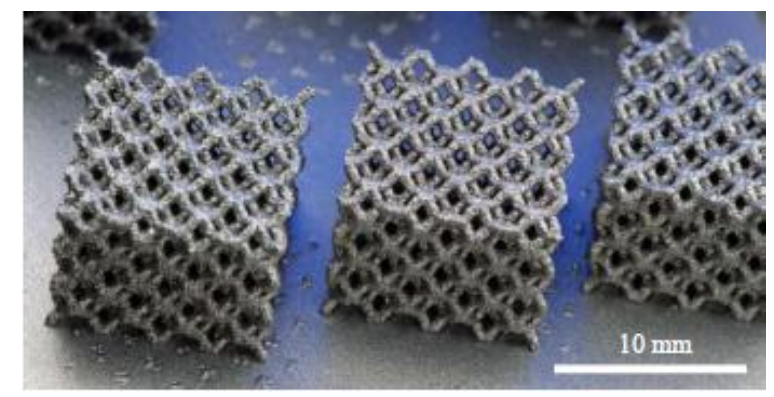

Figure 18. Scaffold-like structures with designed inter-connected porosity out of WE43 made by SLM [65].

\section{Concluding Remarks}

The available studies on the selective laser melting (SLM) of magnesium and magnesium alloy powders are reviewed in this work. Processing parameters involved during SLM and their effects on formability, densification, microstructure and mechanical properties of different magnesium materials are described. It was also demonstrated that the appropriate control of processing parameters is of prime importance for achieving the highest possible dense magnesium parts, and the subsequently required mechanical properties. Analysis of the literature revealed that microstructural evolution in SLM fabricated magnesium alloys has been greatly controlled by the specific laser energy input and because of the high cooling rates achieved, the microstructures produced have been extremely fine. SLM is able to produce bulk magnesium parts with comparable mechanical properties and superior corrosion behaviour to those of as-cast and wrought alloys. Metallurgical defects observed during SLM processing of magnesium alloys such as porosity, thermal cracking, oxide inclusions, and loss of alloying elements were also reviewed.

Research on additive manufacturing (AM) of magnesium based materials has increased in recent years due to the combination of the geometrical freedom offered by AM along with its capability to manufacture components and implants with unique functional properties. The potential of SLM to fabricate topology optimized lightweight magnesium components that are tailored to actual loading cases as well as to produce implants with defined, interconnected pore structures that can substantially improve bone ingrowth has attracted significant interest from the automotive, aerospace, and biomedical sectors. However, compared to iron, titanium, nickel, and aluminium alloys, research on SLM of magnesium based materials is still in its infancy and a considerable amount of research is necessary before these materials see a widespread use in industrial applications. One area that is crucial to establish the SLM process for magnesium powder materials is the ability to produce fully dense parts devoid of balling and oxidation. Only when this capability is routinely and easily achieved can work begin on understanding the influence of processing parameters as well as powder properties on thermal gradients, solidification, residual stresses, and eventually the microstructure/mechanical properties of the SLM fabricated magnesium alloy components. From this, studies can begin to branch out to determine the response of these materials to different loading conditions, as well as to determine the influence of temperature and environmental conditions on their performance towards 
more understanding of the corrosion behaviour and biological response in order to further ascertain the reliability of the products and suitability of SLM technology in producing magnesium alloys.

A critical review shows that the understanding of the microstructural aspects of magnesium alloys produced by SLM is well now developed but the mechanical properties are not widely available. Most available studies have reported only density and hardness values and the mechanical properties such as tensile, compression, and fatigue have not been reported. In the absence of such detailed data, the development of theoretical models is not keeping pace with the experimental work. In addition to the experimental work, modelling and simulation are needed to optimize the properties of the fabricated parts. Particular areas that should be focussed on are the effect of various processing and powder properties. This remains an open research area due to the large number of process/design parameters (e.g., laser power, traverse speed, powder feed rate, layer thickness, hatching pitch, scanning pattern, etc.) involved during SLM. Most of the existing studies have sought only optimal process parameters via extensive experimental work. A major limitation of this approach is that the resulting optimal process parameters may not be useful when experimental conditions (e.g., process or material) change, with the result that new experiments need to-be-conducted from scratch. Further research is needed to lever the information from similar earlier studies and to systematically characterize the relation between process parameters and part features so that the SLM process can be optimized in a more efficient manner. Models that correlate processing conditions to the microstructure and quality of the final product are also needed to minimize the cost and timeline associated with process development. Process specifications for laser melting should be developed to avoid the occurrence of defects to enable reliable production of magnesium alloys. With additional knowledge and application of specific tailoring of the properties, it is likely that SLM of magnesium alloys will see increased usage in forthcoming days.

Author Contributions: Vyasaraj Manakari and Gururaj Parande outlined the review, performed the literature search and wrote the manuscript. Manoj Gupta helped in compiling the wide information related to the topic and data presentation and performed technical editing for all corrections. Manoj Gupta also helped in writing the manuscript and developed the idea of the topic and was responsible for the correspondence.

Conflicts of Interest: The authors declare no conflict of interest.

\section{References}

1. Gupta, M.; Sharon, N.M.L. Magnesium, Magnesium Alloys, and Magnesium Composites; John Wiley \& Sons: Hoboken, NJ, USA, 2011.

2. Mordike, B.; Ebert, T. Magnesium: Properties-Applications-Potential. Mater. Sci. Eng. A 2001, 302, 37-45. [CrossRef]

3. Froes, F.; Eliezer, D.; Aghion, E. The science, technology, and applications of magnesium. JOM 1998, 50, 30-34. [CrossRef]

4. Winzer, N.; Atrens, A.; Song, G.; Ghali, E.; Dietzel, W.; Kainer, K.U.; Hort, N.; Blawert, C. A critical review of the stress corrosion cracking (SCC) of magnesium alloys. Adv. Eng. Mater. 2005, 7, 659-693. [CrossRef]

5. Song, G.L.; Atrens, A. Corrosion mechanisms of magnesium alloys. Adv. Eng. Mater. 1999, 1, 11-33. [CrossRef]

6. Jun, J.; Kim, J.; Park, B.; Kim, K.; Jung, W. Effects of rare earth elements on microstructure and high temperature mechanical properties of ZC63 alloy. J. Mater. Sci. 2005, 40, 2659-2661. [CrossRef]

7. Itoi, T.; Takahashi, K.; Moriyama, H.; Hirohashi, M. A high-strength Mg-Ni-Y alloy sheet with a long-period ordered phase prepared by hot-rolling. Scr. Mater. 2008, 59, 1155-1158. [CrossRef]

8. Toda-Caraballo, I.; Galindo-Nava, E.I.; Rivera-Díaz-del-Castillo, P.E. Understanding the factors influencing yield strength on Mg alloys. Acta Mater. 2014, 75, 287-296. [CrossRef]

9. Johnston, S.; Shi, Z.; Atrens, A. The influence of $\mathrm{pH}$ on the corrosion rate of high-purity Mg, AZ91 and ZE41 in bicarbonate buffered Hanks' solution. Corros. Sci. 2015, 101, 182-192. [CrossRef]

10. Gupta, M.; Meenashisundaram, G.K. Insight into Designing Biocompatible Magnesium Alloys and Composites: Processing, Mechanical and Corrosion Characteristics; Springer: New York, NY, USA, 2015. 
11. Walker, J.; Shadanbaz, S.; Woodfield, T.B.; Staiger, M.P.; Dias, G.J. Magnesium biomaterials for orthopedic application: A review from a biological perspective. J. Biomed. Mater. Res. B Appl. Biomater. 2014, 102, 1316-1331. [CrossRef] [PubMed]

12. Witte, F. The history of biodegradable magnesium implants: A review. Acta Biomater. 2010, 6, 1680-1692. [CrossRef] [PubMed]

13. Windhagen, H.; Radtke, K.; Weizbauer, A.; Diekmann, J.; Noll, Y.; Kreimeyer, U.; Schavan, R.; Stukenborg-Colsman, C.; Waizy, H. Biodegradable magnesium-based screw clinically equivalent to titanium screw in hallux valgus surgery: Short term results of the first prospective, randomized, controlled clinical pilot study. Biomed. Eng. Online 2013, 12, 62. [CrossRef] [PubMed]

14. Sietsema, W. Animal models of cortical porosity. Bone 1995, 17, S297-S305. [CrossRef]

15. Ramirez, J.M.; Hurt, W.C. Bone remodeling in periodontal lesions. J. Periodontol. 1977, 48, 74-77. [CrossRef] [PubMed]

16. Staiger, M.P.; Pietak, A.M.; Huadmai, J.; Dias, G. Magnesium and its alloys as orthopedic biomaterials: A review. Biomaterials 2006, 27, 1728-1734. [CrossRef] [PubMed]

17. Alvarez, K.; Nakajima, H. Metallic scaffolds for bone regeneration. Materials 2009, 2, 790-832. [CrossRef]

18. Agarwal, S.; Curtin, J.; Duffy, B.; Jaiswal, S. Biodegradable magnesium alloys for orthopaedic applications: A review on corrosion, biocompatibility and surface modifications. Mater. Sci. Eng. C 2016, 68, 948-963. [CrossRef] [PubMed]

19. Gehrmann, R.; Frommert, M.M.; Gottstein, G. Texture effects on plastic deformation of magnesium. Mater. Sci. Eng. A 2005, 395, 338-349. [CrossRef]

20. Kulekci, M.K. Magnesium and its alloys applications in automotive industry. Int. J. Adv. Manuf. Technol. 2008, 39, 851-865. [CrossRef]

21. Bettles, C.J. Magnesium powder metallurgy: Process and materials opportunities. J. Mater. Eng. Perform. 2008, 17, 297-301. [CrossRef]

22. Tandon, R.; Madan, D. Emerging applications for magnesium alloy powders. Powder Metall. 2014, 57, 236-241. [CrossRef]

23. Kawamura, Y.; Hayashi, K.; Inoue, A.; Masumoto, T. Rapidly solidified powder metallurgy Mg97Zn1Y2Alloys with excellent tensile yield strength above $600 \mathrm{MPa}$. Mater. Trans. 2001, 42, 1171-1174. [CrossRef]

24. Tandon, R. Potential for Advanced Magnesium Alloy Powders in Aerospace Applications. In Proceedings of the 24th Advanced Aerospace Materials and Processes (AeroMat) Conference and Exposition, Bellevue, WC, USA, 2-5 April 2013.

25. Osakada, K.; Shiomi, M. Flexible manufacturing of metallic products by selective laser melting of powder. Int. J. Mach. Tools Manuf. 2006, 46, 1188-1193. [CrossRef]

26. Riza, S.; Masood, S.; Wen, C. Laser-assisted additive manufacturing for metallic biomedical scaffolds. In Comprehensive Materials Processing; Elsevier: London, UK, 2014.

27. Jia, Q.; Gu, D. Selective laser melting additive manufacturing of Inconel 718 superalloy parts: Densification, microstructure and properties. J. Alloy. Compd. 2014, 585, 713-721. [CrossRef]

28. Zhang, L.C.; Attar, H. Selective laser melting of titanium alloys and titanium matrix composites for biomedical applications: A review. Adv. Eng. Mater. 2016, 18, 463-475. [CrossRef]

29. Wang, X.; Gong, X.; Chou, K. Review on powder-bed laser additive manufacturing of Inconel 718 parts. In Proceedings of the ASME 2015 International Manufacturing Science and Engineering Conference, Charlotte, NC, USA, 8-12 June 2015.

30. Lu, Z.; Cao, J.; Jing, H.; Liu, T.; Lu, F.; Wang, D.; Li, D. Review of main manufacturing processes of complex hollow turbine blades: This paper critically reviews conventional and advanced technologies used for manufacturing hollow turbine blades. Virtual Phys. Prototyp. 2013, 8, 87-95. [CrossRef]

31. Amato, K.; Gaytan, S.; Murr, L.; Martinez, E.; Shindo, P.; Hernandez, J.; Collins, S.; Medina, F. Microstructures and mechanical behavior of Inconel 718 fabricated by selective laser melting. Acta Mater. 2012, 60, 2229-2239. [CrossRef]

32. Oyagüe, R.C.; Sánchez-Turrión, A.; López-Lozano, J.F.; Montero, J.; Albaladejo, A.; Suárez-García, M.J. Evaluation of fit of cement-retained implant-supported 3-unit structures fabricated with direct metal laser sintering and vacuum casting techniques. Odontology 2012, 100, 249-253. [CrossRef] [PubMed]

33. Sercombe, T.; Li, X. Selective laser melting of aluminium and aluminium metal matrix composites: Review. Mater. Technol. 2016, 31, 77-85. [CrossRef] 
34. Kruth, J.-P.; Mercelis, P.; van Vaerenbergh, J.; Froyen, L.; Rombouts, M. Binding mechanisms in selective laser sintering and selective laser melting. Rapid Prototyp. J. 2005, 11, 26-36. [CrossRef]

35. Yadroitsev, I.; Smurov, I. Surface morphology in selective laser melting of metal powders. Phys. Procedia 2011, 12, 264-270. [CrossRef]

36. Fischer, P.; Romano, V.; Weber, H.-P.; Karapatis, N.; Boillat, E.; Glardon, R. Sintering of commercially pure titanium powder with a Nd:YAG laser source. Acta Mater. 2003, 51, 1651-1662. [CrossRef]

37. Yadroitsev, I.; Yadroitsava, I.; Smurov, I. Strategy of fabrication of complex shape parts based on the stability of single laser melted track. SPIE Proc. 2011, 7921. [CrossRef]

38. Li, Y.; Gu, D. Parametric analysis of thermal behavior during selective laser melting additive manufacturing of aluminum alloy powder. Mater. Des. 2014, 63, 856-867. [CrossRef]

39. Gu, D. Laser Additive Manufacturing of High-Performance Materials; Springer: New York, NY, USA, 2015.

40. Zhang, H.; Zhang, D.; Ma, C.; Guo, S. Improving mechanical properties and corrosion resistance of Mg-6Zn-Mn magnesium alloy by rapid solidification. Mater. Lett. 2013, 92, 45-48. [CrossRef]

41. Yap, C.; Chua, C.; Dong, Z.; Liu, Z.; Zhang, D.; Loh, L.; Sing, S.L. Review of selective laser melting: Materials and applications. Appl. Phys. Rev. 2015, 2, 041101. [CrossRef]

42. Sing, S.L.; An, J.; Yeong, W.Y.; Wiria, F.E. Laser and electron-beam powder-bed additive manufacturing of metallic implants: A review on processes, materials and designs. J. Orthop. Res. 2016, 34, 369-385. [CrossRef] [PubMed]

43. Acharya, R.; Bansal, R.; Gambone, J.J.; Das, S. A coupled thermal, fluid flow, and solidification model for the processing of single-crystal alloy CMSX-4 through scanning laser epitaxy for turbine engine hot-section component repair (part I). Metall. Mater. Trans. B 2014, 45, 2247-2261. [CrossRef]

44. Acharya, R.; Bansal, R.; Gambone, J.J.; Kaplan, M.A.; Fuchs, G.E.; Rudawski, N.; Das, S. Additive manufacturing and characterization of rené 80 superalloy processed through scanning laser epitaxy for turbine engine hot-section component repair. Adv. Eng. Mater. 2015, 17, 942-950. [CrossRef]

45. Liu, Z.; Zhang, D.; Sing, S.; Chua, C.; Loh, L. Interfacial characterization of SLM parts in multi-material processing: Metallurgical diffusion between 316L stainless steel and C18400 copper alloy. Mater. Charact. 2014, 94, 116-125. [CrossRef]

46. Sing, S.; Lam, L.; Zhang, D.; Liu, Z.; Chua, C. Interfacial characterization of SLM parts in multi-material processing: Intermetallic phase formation between AlSi10Mg and C18400 copper alloy. Mater. Charact. 2015, 107, 220-227. [CrossRef]

47. Kruth, J.-P.; Badrossamay, M.; Yasa, E.; Deckers, J.; Thijs, L.; van Humbeeck, J. Part and material properties in selective laser melting of metals. In Proceedings of the 16th International Symposium on Electromachining, Shanghai, China, 19-23 April 2010.

48. Kruth, J.-P.; Levy, G.; Klocke, F.; Childs, T. Consolidation phenomena in laser and powder-bed based layered manufacturing. CIRP Ann. Manuf. Technol. 2007, 56, 730-759. [CrossRef]

49. Shuai, C.; Yang, Y.; Wu, P.; Lin, X.; Liu, Y.; Zhou, Y.; Feng, P.; Liu, X.; Peng, S. Laser rapid solidification improves corrosion behavior of Mg-Zn-Zr alloy. J. Alloy. Compd. 2017, 691, 961-969. [CrossRef]

50. Das, S. Physical aspects of process control in selective laser sintering of metals. Adv. Eng. Mater. 2003, 5, 701-711. [CrossRef]

51. Gu, D.; Meiners, W.; Wissenbach, K.; Poprawe, R. Laser additive manufacturing of metallic components: Materials, processes and mechanisms. Int. Mater. Rev. 2012, 57, 133-164. [CrossRef]

52. Olakanmi, E.; Cochrane, R.; Dalgarno, K. A review on selective laser sintering/melting (SLS/SLM) of aluminium alloy powders: Processing, microstructure, and properties. Prog. Mater. Sci. 2015, 74, 401-477. [CrossRef]

53. Niu, H.; Chang, I. Selective laser sintering of gas atomized M2 high speed steel powder. J. Mater. Sci. 2000, 35, 31-38. [CrossRef]

54. Agarwala, M.; Bourell, D.; Beaman, J.; Marcus, H.; Barlow, J. Direct selective laser sintering of metals. Rapid Prototyp. J. 1995, 1, 26-36. [CrossRef]

55. Ng, C.; Savalani, M.; Man, H.; Gibson, I. Layer manufacturing of magnesium and its alloy structures for future applications. Virtual Phys. Prototyp. 2010, 5, 13-19. [CrossRef]

56. Ng, C.C.; Savalani, M.M.; Man, H.C. Fabrication of magnesium using selective laser melting technique. Rapid Prototyp. J. 2011, 17, 479-490. 
57. Ng, C.C.; Savalani, M.M.; Lau, M.L.; Man, H.C. Microstructure and mechanical properties of selective laser melted magnesium. Appl. Surf. Sci. 2011, 257, 7447-7454. [CrossRef]

58. Savalani, M.M.; Pizarro, J.M.; Campbell, R.I.; Gibson, I. Effect of preheat and layer thickness on selective laser melting (SLM) of magnesium. Rapid Prototyp. J. 2016, 22, 115-122. [CrossRef]

59. Hu, D.; Wang, Y.; Zhang, D.; Hao, L.; Jiang, J.; Li, Z.; Chen, Y. Experimental investigation on selective laser melting of bulk net-shape pure magnesium. Mater. Manuf. Process. 2015, 30, 1298-1304. [CrossRef]

60. Zhang, B.; Liao, H.; Coddet, C. Effects of processing parameters on properties of selective laser melting Mg-9\%Al powder mixture. Mater. Des. 2012, 34, 753-758. [CrossRef]

61. Wei, K.; Gao, M.; Wang, Z.; Zeng, X. Effect of energy input on formability, microstructure and mechanical properties of selective laser melted AZ91D magnesium alloy. Mater. Sci. Eng. A 2014, 611, 212-222. [CrossRef]

62. Wei, K.; Wang, Z.; Zeng, X. Influence of element vaporization on formability, composition, microstructure, and mechanical performance of the selective laser melted Mg-Zn-Zr components. Mater. Lett. 2015, 156, 187-190. [CrossRef]

63. Zhang, C. Parametric Study on Selective Laser Melting of Magnesium Micropowder with Hydroxyapatite (HA) Nanoparticles; University of California: Los Angeles, CA, USA, 2015.

64. Gieseke, M.; Noelke, C.; Kaierle, S.; Wesling, V.; Haferkamp, H.; Hort, N. Selective laser melting of magnesium and magnesium alloys. Magnes. Technol. 2013, 2013, 65-68.

65. Jauer, L.; Jülich, B.; Voshage, M.; Meiners, W. Selective laser melting of magnesium alloys. In Proceedings of the 7th Symposium on Biodegradable Metals, Carovigno, Italy, 23-28 August 2015; p. 1.

66. Yang, Y.; Wu, P.; Wang, Q.; Wu, H.; Liu, Y.; Deng, Y.; Zhou, Y.; Shuai, C. The enhancement of Mg corrosion resistance by alloying $\mathrm{Mn}$ and laser-melting. Materials 2016, 9, 216. [CrossRef]

67. Song, B.; Dong, S.; Deng, S.; Liao, H.; Coddet, C. Microstructure and tensile properties of iron parts fabricated by selective laser melting. Opt. Laser Technol. 2014, 56, 451-460. [CrossRef]

68. Attar, H.; Calin, M.; Zhang, L.; Scudino, S.; Eckert, J. Manufacture by selective laser melting and mechanical behavior of commercially pure titanium. Mater. Sci. Eng. A 2014, 593, 170-177. [CrossRef]

69. Attar, H.; Bönisch, M.; Calin, M.; Zhang, L.-C.; Scudino, S.; Eckert, J. Selective laser melting of in situ titanium-titanium boride composites: Processing, microstructure and mechanical properties. Acta Mater. 2014, 76, 13-22. [CrossRef]

70. Yadroitsev, I.; Krakhmalev, P.; Yadroitsava, I. Hierarchical design principles of selective laser melting for high quality metallic objects. Addit. Manuf. 2015, 7, 45-56. [CrossRef]

71. Niu, H.; Chang, I. Instability of scan tracks of selective laser sintering of high speed steel powder. Scr. Mater. 1999, 41, 1229-1234. [CrossRef]

72. Olakanmi, E. Selective laser sintering/melting (SLS/SLM) of pure Al, Al-Mg, and Al-Si powders: Effect of processing conditions and powder properties. J. Mater. Process. Technol. 2013, 213, 1387-1405. [CrossRef]

73. Gu, D.; Shen, Y. Balling phenomena in direct laser sintering of stainless steel powder: Metallurgical mechanisms and control methods. Mater. Des. 2009, 30, 2903-2910. [CrossRef]

74. Khan, M.; Dickens, P. Selective laser melting (SLM) of gold (Au). Rapid Prototyp. J. 2012, 18, 81-94. [CrossRef]

75. Gu, D.; Hagedorn, Y.-C.; Meiners, W.; Meng, G.; Batista, R.J.S.; Wissenbach, K.; Poprawe, R. Densification behavior, microstructure evolution, and wear performance of selective laser melting processed commercially pure titanium. Acta Mater. 2012, 60, 3849-3860. [CrossRef]

76. Thijs, L.; Verhaeghe, F.; Craeghs, T.; van Humbeeck, J.; Kruth, J.-P. A study of the microstructural evolution during selective laser melting of Ti-6Al-4V. Acta Mater. 2010, 58, 3303-3312. [CrossRef]

77. Aboulkhair, N.T.; Everitt, N.M.; Ashcroft, I.; Tuck, C. Reducing porosity in AlSi10Mg parts processed by selective laser melting. Addit. Manuf. 2014, 1, 77-86. [CrossRef]

78. Zhang, L.; Klemm, D.; Eckert, J.; Hao, Y.; Sercombe, T. Manufacture by selective laser melting and mechanical behavior of a biomedical Ti-24Nb-4Zr-8Sn alloy. Scr. Mater. 2011, 65, 21-24. [CrossRef]

79. Attar, H.; Prashanth, K.G.; Zhang, L.-C.; Calin, M.; Okulov, I.V.; Scudino, S.; Yang, C.; Eckert, J. Effect of powder particle shape on the properties of in situ Ti-TiB composite materials produced by selective laser melting. J. Mater. Sci. Technol. 2015, 31, 1001-1005. [CrossRef]

80. Krishna, B.V.; Bose, S.; Bandyopadhyay, A. Low stiffness porous Ti structures for load-bearing implants. Acta Biomater. 2007, 3, 997-1006. [CrossRef] [PubMed]

81. Taltavull, C.; Torres, B.; López, A.; Rodrigo, P.; Otero, E.; Rams, J. Selective laser surface melting of a magnesium-aluminium alloy. Mater. Lett. 2012, 85, 98-101. [CrossRef] 
82. Amorim, F.L.; Lohrengel, A.; Neubert, V.; Higa, C.F.; Czelusniak, T. Selective laser sintering of Mo-CuNi composite to be used as EDM electrode. Rapid Prototyp. J. 2014, 20, 59-68. [CrossRef]

83. Hon, K.K.B. Digital Additive Manufacturing: From Rapid Prototyping to Rapid Manufacturing; Springer: London, UK, 2007; pp. 337-340.

84. Olakanmi, E.; Cochrane, R.; Dalgarno, K. Densification mechanism and microstructural evolution in selective laser sintering of Al-12Si powders. J. Mater. Process. Technol. 2011, 211, 113-121. [CrossRef]

85. Tolochko, N.; Mozzharov, S.; Laoui, T.; Froyen, L. Selective laser sintering of single-and two-component metal powders. Rapid Prototyp. J. 2003, 9, 68-78. [CrossRef]

86. Sames, W.; List, F.; Pannala, S.; Dehoff, R.; Babu, S. The metallurgy and processing science of metal additive manufacturing. Int. Mater. Rev. 2016, 61, 315-360. [CrossRef]

87. Niu, H.; Chang, I. Selective laser sintering of gas and water atomized high speed steel powders. Scr. Mater. 1999, 41, 25-30. [CrossRef]

88. Simchi, A. The role of particle size on the laser sintering of iron powder. Metall. Mater. Trans. B 2004, 35, 937-948. [CrossRef]

89. Liu, B.; Wildman, R.; Tuck, C.; Ashcroft, I.; Hague, R. Investigation the effect of particle size distribution on processing parameters optimisation in selective laser melting process. In International Solid Freeform Fabrication Symposium: An Additive Manufacturing Conference; University of Texas: Austin, TX, USA, 2011; pp. 227-238.

90. Kumar, S. 10.05-Selective Laser Sintering/Melting A2-Hashmi, Saleem. In Comprehensive Materials Processing; Batalha, G.F., Tyne, C.J.V., Yilbas, B., Eds.; Elsevier: Oxford, UK, 2014; pp. 93-134.

91. Olatunde Olakanmi, E.; Dalgarno, K.W.; Cochrane, R.F. Laser sintering of blended Al-Si powders. Rapid Prototyp. J. 2012, 18, 109-119. [CrossRef]

92. Bourell, D.; Stucker, B.; Spierings, A.; Herres, N.; Levy, G. Influence of the particle size distribution on surface quality and mechanical properties in AM steel parts. Rapid Prototyp. J. 2011, 17, 195-202.

93. Glardon, R.; Karapatis, N.; Romano, V.; Levy, G. Influence of Nd:YAG parameters on the selective laser sintering of metallic powders. CIRP Ann. Manuf. Technol. 2001, 50, 133-136. [CrossRef]

94. Cao, X.; Jahazi, M.; Immarigeon, J.; Wallace, W. A review of laser welding techniques for magnesium alloys. J. Mater. Process. Technol. 2006, 171, 188-204. [CrossRef]

95. Tolochko, N.K.; Khlopkov, Y.V.; Mozzharov, S.E.; Ignatiev, M.B.; Laoui, T.; Titov, V.I. Absorptance of powder materials suitable for laser sintering. Rapid Prototyp. J. 2000, 6, 155-161. [CrossRef]

96. Steen, W. Laser material processing-An overview. J. Opt. A Pure Appl. Opt. 2003, 5, S3. [CrossRef]

97. John, F. Ready: LIA Handbook of Laser Materials Processing; Laser Institute of America Magnolia Publishing Inc.: Orlando, FL, USA, 2001; pp. 181-183.

98. Shen, N.; Chou, K. Thermal modeling of electron beam additive manufacturing process: Powder sintering effects. In Proceedings of the ASME 2012 International Manufacturing Science and Engineering Conference collocated with the 40th North American Manufacturing Research Conference and in participation with the International Conference on Tribology Materials and Processing, Notre Dame, IN, USA, 4-8 June 2012; pp. 287-295.

99. Selcuk, C. Laser metal deposition for powder metallurgy parts. Powder Metall. 2011, 54, 94-99.

100. Basu, B.; Date, A. Rapid solidification following laser melting of pure metals-I. Study of flow field and role of convection. Int. J. Heat Mass Transf. 1992, 35, 1049-1058. [CrossRef]

101. Bontha, S.; Klingbeil, N.W.; Kobryn, P.A.; Fraser, H.L. Thermal process maps for predicting solidification microstructure in laser fabrication of thin-wall structures. J. Mater. Process. Technol. 2006, 178, 135-142. [CrossRef]

102. Dahle, A.K.; Lee, Y.C.; Nave, M.D.; Schaffer, P.L.; StJohn, D.H. Development of the as-cast microstructure in magnesium-aluminium alloys. J. Light Met. 2001, 1, 61-72. [CrossRef]

103. Campbell, J. Castings; Butterworth-Heinemann: Oxford, UK, 2003.

104. Aarstad, K. Protective Films on Molten Magnesium. Ph.D. Thesis, Norwegian University of Science and Technology, Trondheim, Norway, May 2004.

105. Louvis, E.; Fox, P.; Sutcliffe, C.J. Selective laser melting of aluminium components. J. Mater. Process. Technol. 2011, 211, 275-284. [CrossRef]

106. Collur, M.; Paul, A.; DebRoy, T. Mechanism of alloying element vaporization during laser welding. Metall. Trans. B 1987, 18, 733-740. [CrossRef] 
107. Sanders, P.; Keske, J.; Leong, K.; Kornecki, G. High power Nd: YAG and $\mathrm{CO}_{2}$ laser welding of magnesium. J. Laser Appl. 1999, 11, 96-103. [CrossRef]

108. Liu, Y.; Li, S.; Wang, H.; Hou, W.; Hao, Y.; Yang, R.; Sercombe, T.B.; Zhang, L.C. Microstructure, defects and mechanical behavior of beta-type titanium porous structures manufactured by electron beam melting and selective laser melting. Acta Mater. 2016, 113, 56-67. [CrossRef]

109. Asgharzadeh, H.; Simchi, A. Effect of sintering atmosphere and carbon content on the densification and microstructure of laser-sintered M2 high-speed steel powder. Mater. Sci. Eng. A 2005, 403, 290-298. [CrossRef]

110. Gu, D.; Shen, Y. Balling phenomena during direct laser sintering of multi-component Cu-based metal powder. J. Alloy. Compd. 2007, 432, 163-166. [CrossRef]

111. Zhang, L.-C.; Attar, H.; Calin, M.; Eckert, J. Review on manufacture by selective laser melting and properties of titanium based materials for biomedical applications. Mater. Technol. 2016, 31, 66-76. [CrossRef]

112. Li, R.; Liu, J.; Shi, Y.; Wang, L.; Jiang, W. Balling behavior of stainless steel and nickel powder during selective laser melting process. Int. J. Adv. Manuf. Technol. 2012, 59, 1025-1035. [CrossRef]

113. Mercelis, P.; Kruth, J.-P. Residual stresses in selective laser sintering and selective laser melting. Rapid Prototyp. J. 2006, 12, 254-265. [CrossRef]

114. Parande, G.; Manakari, V.; Meenashisundaram, G.K.; Gupta, M. Enhancing the hardness/compression/ damping response of magnesium by reinforcing with biocompatible silica nanoparticulates. Int. J. Mater. Res. 2016, 107, 1091-1099. [CrossRef]

115. Casavola, C.; Campanelli, S.; Pappalettere, C. Preliminary investigation on distribution of residual stress generated by the selective laser melting process. J. Strain Anal. Eng. Des. 2009, 44, 93-104. [CrossRef]

116. Shamsaei, N.; Yadollahi, A.; Bian, L.; Thompson, S.M. An overview of Direct Laser Deposition for additive manufacturing; Part II: Mechanical behavior, process parameter optimization and control. Addit. Manuf. 2015, 8, 12-35. [CrossRef]

117. Atrens, A.; Song, G.-L.; Cao, F.; Shi, Z.; Bowen, P.K. Advances in Mg corrosion and research suggestions. J. Magnes. Alloy. 2013, 1, 177-200. [CrossRef]

118. Song, G.; Atrens, A. Understanding magnesium corrosion-A framework for improved alloy performance. Adv. Eng. Mater. 2003, 5, 837-858. [CrossRef]

119. Ghali, E. Corrosion Resistance of Aluminum and Magnesium Alloys: Understanding, Performance, and Testing; John Wiley \& Sons: Hoboken, NJ, USA, 2010.

120. Singh, A.; Harimkar, S.P. Laser surface engineering of magnesium alloys: A review. JOM 2012, 64, 716-733. [CrossRef]

121. Guan, Y.; Zhou, W.; Zheng, H.; Li, Z. Solidification microstructure of AZ91D Mg alloy after laser surface melting. Appl. Phys. A 2010, 101, 339-344. [CrossRef]

122. Liu, C.; Liang, J.; Zhou, J.; Wang, L.; Li, Q. Effect of laser surface melting on microstructure and corrosion characteristics of AM60B magnesium alloy. Appl. Surf. Sci. 2015, 343, 133-140. [CrossRef]

123. Cui, Z.-Q.; Shi, H.-X.; Wang, W.-X.; Xu, B.-S. Laser surface melting AZ31B magnesium alloy with liquid nitrogen-assisted cooling. Trans. Nonferr. Met. Soc. China 2015, 25, 1446-1453. [CrossRef]

124. Taltavull, C.; Torres, B.; Lopez, A.; Rodrigo, P.; Otero, E.; Atrens, A.; Rams, J. Corrosion behaviour of laser surface melted magnesium alloy AZ91D. Mater. Des. 2014, 57, 40-50. [CrossRef]

125. Paital, S.R.; Bhattacharya, A.; Moncayo, M.; Ho, Y.H.; Mahdak, K.; Nag, S.; Banerjee, R.; Dahotre, N.B. Improved corrosion and wear resistance of $\mathrm{Mg}$ alloys via laser surface modification of $\mathrm{Al}$ on $\mathrm{AZ31B}$. Surf. Coat. Technol. 2012, 206, 2308-2315. [CrossRef]

126. Coy, A.; Viejo, F.; Garcia-Garcia, F.; Liu, Z.; Skeldon, P.; Thompson, G. Effect of excimer laser surface melting on the microstructure and corrosion performance of the die cast AZ91D magnesium alloy. Corros. Sci. 2010, 52, 387-397. [CrossRef]

127. Raman, R.S.; Murray, S.; Brandt, M. Laser assisted modification of surface microstructure for localised corrosion resistance of magnesium alloys. Surf. Eng. 2013, 23, 107-111. [CrossRef]

128. Abbas, G.; Liu, Z.; Skeldon, P. Corrosion behaviour of laser-melted magnesium alloys. Appl. Surf. Sci. 2005, 247, 347-353. [CrossRef]

129. Makar, G.; Kruger, J. Corrosion of magnesium. Int. Mater. Rev. 2013, 38, 138-153. [CrossRef]

130. Liu, C.; Li, Q.; Liang, J.; Zhou, J.; Wang, L. Microstructure and corrosion behaviour of laser surface melting treated WE43 magnesium alloy. RSC Adv. 2016, 6, 30642-30651. [CrossRef] 
131. Song, G. Control of biodegradation of biocompatable magnesium alloys. Corros. Sci. 2007, 49, $1696-1701$. [CrossRef]

132. Gu, X.; Li, N.; Zheng, Y.; Ruan, L. In vitro degradation performance and biological response of a Mg-Zn-Zr alloy. Mater. Sci. Eng. B 2011, 176, 1778-1784. [CrossRef]

133. Dai, N.; Zhang, L.-C.; Zhang, J.; Chen, Q.; Wu, M. Corrosion behavior of selective laser melted Ti-6Al-4V alloy in $\mathrm{NaCl}$ solution. Corros. Sci. 2016, 102, 484-489. [CrossRef]

134. Dai, N.; Zhang, L.-C.; Zhang, J.; Zhang, X.; Ni, Q.; Chen, Y.; Wu, M.; Yang, C. Distinction in corrosion resistance of selective laser melted Ti-6Al-4V alloy on different planes. Corros. Sci. 2016, 111, 703-710. [CrossRef]

135. Xin, Y.; Hu, T.; Chu, P. In vitro studies of biomedical magnesium alloys in a simulated physiological environment: A review. Acta Biomater. 2011, 7, 1452-1459. [CrossRef] [PubMed]

136. Rettig, R.; Virtanen, S. Time-dependent electrochemical characterization of the corrosion of a magnesium rare-earth alloy in simulated body fluids. J. Biomed. Mater. Res. A 2008, 85, 167-175. [CrossRef] [PubMed]

137. Martin, R. Porosity and specific surface of bone. Crit. Rev. Biomed. Eng. 1983, 10, 179-222.

138. Bentolila, V.; Boyce, T.; Fyhrie, D.; Drumb, R.; Skerry, T.; Schaffler, M. Intracortical remodeling in adult rat long bones after fatigue loading. Bone 1998, 23, 275-281. [CrossRef]

139. Prendergast, P.; Huiskes, R. Microdamage and osteocyte-lacuna strain in bone: A microstructural finite element analysis. J. Biomech. Eng. 1996, 118, 240-246. [CrossRef] [PubMed]

140. Wang, X.; Ni, Q. Determination of cortical bone porosity and pore size distribution using a low field pulsed NMR approach. J. Orthop. Res. 2003, 21, 312-319. [CrossRef]

141. Kufahl, R.H.; Saha, S. A theoretical model for stress-generated fluid flow in the canaliculi-lacunae network in bone tissue. J. Biomech. 1990, 23, 171-180. [CrossRef]

142. Zardiackas, L.D.; Parsell, D.E.; Dillon, L.D.; Mitchell, D.W.; Nunnery, L.A.; Poggie, R. Structure, metallurgy, and mechanical properties of a porous tantalum foam. J. Biomed. Mater. Res. 2001, 58, 180-187. [CrossRef]

143. Lefebvre, L.-P.; Banhart, J.; Dunand, D. Porous metals and metallic foams: Current status and recent developments. Adv. Eng. Mater. 2008, 10, 775-787. [CrossRef]

144. Yan, C.; Hao, L.; Hussein, A.; Young, P.; Raymont, D. Advanced lightweight 316L stainless steel cellular lattice structures fabricated via selective laser melting. Mater. Des. 2014, 55, 533-541. [CrossRef]

145. Nakajima, H. Fabrication, properties and application of porous metals with directional pores. Prog. Mater. Sci. 2007, 52, 1091-1173. [CrossRef]

146. Evans, A.G.; Hutchinson, J.W.; Fleck, N.A.; Ashby, M.; Wadley, H. The topological design of multifunctional cellular metals. Prog. Mater. Sci. 2001, 46, 309-327. [CrossRef]

147. Bose, S.; Vahabzadeh, S.; Bandyopadhyay, A. Bone tissue engineering using 3D printing. Mater. Today 2013, 16, 496-504. [CrossRef]

148. Hollister, S.J. Porous scaffold design for tissue engineering. Nat. Mater. 2005, 4, 518-524. [CrossRef] [PubMed]

149. Challis, V.J.; Xu, X.; Zhang, L.C.; Roberts, A.P.; Grotowski, J.F.; Sercombe, T.B. High specific strength and stiffness structures produced using selective laser melting. Mater. Des. 2014, 63, 783-788. [CrossRef]

150. Liu, Y.; Li, X.; Zhang, L.; Sercombe, T. Processing and properties of topologically optimised biomedical Ti-24Nb-4Zr-8Sn scaffolds manufactured by selective laser melting. Mater. Sci. Eng. A 2015, 642, 268-278. [CrossRef]

151. Attar, H.; Löber, L.; Funk, A.; Calin, M.; Zhang, L.; Prashanth, K.; Scudino, S.; Zhang, Y.S.; Eckert, J. Mechanical behavior of porous commercially pure $\mathrm{Ti}$ and $\mathrm{Ti}-\mathrm{TiB}$ composite materials manufactured by selective laser melting. Mater. Sci. Eng. A 2015, 625, 350-356. [CrossRef]

(C) 2016 by the authors; licensee MDPI, Basel, Switzerland. This article is an open access article distributed under the terms and conditions of the Creative Commons Attribution (CC-BY) license (http://creativecommons.org/licenses/by/4.0/). 